\title{
Environment and Mechanisms of Severe Turbulence in a Midlatitude Cyclone
}

\author{
Stanley B. Trier, ${ }^{\mathrm{a}}$ Robert D. Sharman, ${ }^{\mathrm{a}}$ Domingo Muñoz-EsParza, ${ }^{\mathrm{a}}$ And Todd P. LANE ${ }^{\mathrm{b}}$ \\ ${ }^{\mathrm{a}}$ National Center for Atmospheric Research, Boulder, Colorado; ${ }^{\mathrm{b}}$ School of Earth Sciences, and ARC Centre of Excellence for \\ Climate Extremes, University of Melbourne, Melbourne, Victoria, Australia
}

(Manuscript received 26 March 2020, in final form 13 August 2020)

\begin{abstract}
A large midlatitude cyclone occurred over the central United States from 0000 to 1800 UTC 30 April 2017. During this period, there were more than 1100 reports of moderate-or-greater turbulence at commercial aviation cruising altitudes east of the Rocky Mountains. Much of this turbulence was located above or, otherwise, outside the synoptic-scale cloud shield of the cyclone, thus complicating its avoidance. In this study we use two-way nesting in a numerical model with finest horizontal spacing of $370 \mathrm{~m}$ to investigate possible mechanisms producing turbulence in two distinct regions of the cyclone. In both regions, model-parameterized turbulence kinetic energy compares well to observed turbulence reports. Despite being outside of hazardous large radar reflectivity locations in deep convection, both regions experienced strong modification of the turbulence environment as a result of upper-tropospheric/lower-stratospheric (UTLS) convective outflow. For one region, where turbulence was isolated and short lived, simulations revealed breaking of $\sim 100-\mathrm{km}$ horizontal-wavelength lower-stratospheric gravity waves in the exit region of a UTLS jet streak as the most likely mechanism for the observed turbulence. Although similar waves occurred in a simulation without convection, the altitude at which wave breaking occurred in the control simulation was strongly affected by UTLS outflow from distant deep convection. In the other analyzed region, turbulence was more persistent and widespread. There, overturning waves of much shorter 5-10-km horizontal wavelengths occurred within layers of gradient Richardson number $<0.25$, which promoted Kelvin-Helmholtz instability associated with strong vertical shear in different horizontal locations both above and beneath the convectively enhanced UTLS jet.
\end{abstract}

KEYWORDS: Deep convection; Gravity waves; Kelvin-Helmholtz instabilities; Turbulence; Mesoscale processes

\section{Introduction}

Severe turbulence encounters are disruptive to commercial aviation due to the risk of inflight injuries to passengers and crew, and their indirect influence on annual airline operating costs (e.g., Sharman 2016). Clear-air turbulence (CAT), in particular, is difficult to anticipate and detect using available hazard identification technologies including radar, satellite, and lightning detection networks. Well-developed baroclinic wave cyclones provide a synoptic environment within which CAT often occurs. In the current study we use observations and high-resolution simulations to examine both the environment of the turbulence and its different onset mechanisms in a midlatitude cyclone having widespread moderate-or-greater (MOG) turbulence.

Both vertical shear and deformation of the horizontal flow can enhance susceptibility to CAT (e.g., Mancuso and Endlich 1966; Ellrod and Knapp 1992). Exit regions of upper-tropospheric/lower-stratospheric (UTLS) jet streaks and col regions downstream of cutoff lows (Ellrod and Knapp 1992, their Fig. 3) $)^{1}$ are typical locations of strong deformation in baroclinic wave cyclones. From purely kinematic considerations, vertical shear of the horizontal wind is enhanced in locations both immediately above and beneath UTLS jets.

\footnotetext{
${ }^{1} \mathrm{~A}$ col is defined as a location between two opposing circulations at which the horizontal flow becomes zero.
}

Corresponding author: Stanley B. Trier, trier@ucar.edu
These vertical shear layers can influence turbulence development from Kelvin-Helmholtz (KH) instability when the gradient Richardson number drops below a critical value (Miles and Howard 1964; Miles 1986). Other wave cyclone features that are susceptible to turbulence include upper-level fronts (e.g., Shapiro 1978; Koch et al. 2005), tropopause folds (e.g., Danielsen 1968; Kennedy and Shapiro 1980; Shapiro 1980; Koch et al. 2005), and their associated internal- and inertia-gravity waves (e.g., Lane et al. 2004; Koch et al. 2005; Plougonven and Zhang 2016).

Although many aspects concerning the formation of these favorable regions for UTLS turbulence in midlatitude cyclones may be understood in terms of dry semigeostrophic processes (Keyser and Shapiro 1986), organized deep convection can play an important role in their precise location, structure and intensity from effects of latent heat release on the synoptic pattern. Furthermore, local vertical shear increases (e.g., Trier et al. 2010, 2012; Zovko-Rajak and Lane 2014; Zovko-Rajak et al. 2019) and/or static stability decreases (e.g., Trier et al. 2010; Kim et al. 2014) that facilitate turbulence at altitudes near the UTLS jet can be strongly influenced by anticyclonic outflow emanating directly from distant organized deep convection.

In addition, mesoscale deep convection can excite internal gravity waves ranging in horizontal scales of a few to tens (e.g., Fovell et al. 1992; Lane et al. 2003; Lane and Knievel 2005; Koch et al. 2005; Lane and Sharman 2008; Trier et al. 2012) up to several hundreds of km (e.g., Trier and Sharman 2016; Zovko-Rajak et al. 2019), which can initiate clear-air turbulence [see e.g., Sharman and Trier (2019) for a review]. 
The mechanisms of turbulence initiation due to gravity waves vary from wave breaking near critical levels (e.g., Dörnbrack et al. 1995) to more indirect initiation arising from modifications of environmental vertical shear and static stability within the wave, which can permit $\mathrm{KH}$ instability. Significant environmental modifications occur most often for gravity waves with large horizontal and small vertical wavelengths, which have larger vertical tilt than waves with small horizontal and large vertical wavelengths (Fritts and Alexander 2003; Lane et al. 2004; Plougonven and Zhang 2016).

The horizontal scales that directly affect turbulence on medium-to-large sized commercial aircraft are restricted to the range of 10 to $2000 \mathrm{~m}$ (e.g., Lane et al. 2012). Large-eddy simulations (LES), which have grid spacings of $\sim 100 \mathrm{~m}$ or less are able to resolve the largest of these scales (e.g., Lane and Sharman 2014), which may contain the majority of the turbulent kinetic energy (TKE). However, model domain sizes in LES-type simulations are highly constrained by computational expense and data storage requirements at these high resolutions.

Since we seek to simulate the evolution of subsynoptic features within the baroclinic wave cyclone that are important to the onset of turbulence, we use an alternative modeling approach of two-way interactive nesting in a numerical weather prediction (NWP) model. Though unable to explicitly resolve the turbulence, previous studies (e.g., Trier et al. 2010, 2012; Kim and Chun 2010, 2012; Kim et al. 2014; Zovko-Rajak and Lane 2014; Trier and Sharman 2018; Barber et al. 2018) have indicated that such simulations having finest horizontal grid spacings of $\sim 500 \mathrm{~m}$ are able to resolve many different mechanisms that can initiate turbulence. Using nested NWP simulations, we diagnose different possible mechanisms for UTLS turbulence in different turbulence-prone regions of the baroclinic wave cyclone including col and jet exit regions, and tropopause folds. We focus in particular on CAT, and the effects of distant organized convection, on the onset of turbulence in regions either above or horizontally displaced from the synoptic-scale cloud shield of the midlatitude cyclone.

\section{Turbulence observations on 30 April 2017}

\section{a. Data}

The flight level turbulence data used in this study include both pilot reports (PIREPs) and in situ measurements currently recorded on a subset of commercial airliners. In contrast to PIREP turbulence intensities, which are subjective and based on the perceptions of aircrew, the in situ data are quantitative estimates of the eddy dissipation rate (EDR) $\varepsilon^{1 / 3}\left(\mathrm{~m}^{2 / 3} \mathrm{~s}^{-1}\right)$ derived from vertical motion. Only a minority of U.S. airliners are equipped with these automated turbulence detection systems. However, they continuously record maximum turbulence values at 1-min frequency, in contrast to PIREPs, which are highly intermittent. Thus, the in situ measurements provide a substantial fraction of the reported turbulence. Our categorization of EDR ranges for different turbulence intensities of $0.15-0.21,0.22-0.47$, and $>0.47$, for light, moderate, and severe, respectively, are broadly consistent with thresholds used for medium-sized commercial aircraft in recent studies (e.g., Lane and Sharman 2014; Sharman et al. 2014).

Twice-daily National Weather Service (NWS) sounding data, together with gridded Global Forecast System (GFS) analyses characterize the environment in which the turbulence occurs. UTLS temperature and humidity from these data sources are also analyzed alongside NEXRAD WSR-88D data and imagery of infrared satellite brightness temperature to assess whether observed turbulence occurs within or outside of clouds and precipitation.

\section{b. Turbulence reports}

From 0000 to 1800 UTC 30 April 2017 there were over 1100 reports of moderate-or-greater (MOG) turbulence at cruising altitudes $(z>24 \mathrm{kft}$ or $\sim 7.3 \mathrm{~km} \mathrm{MSL} ; p \leq 400 \mathrm{hPa})$ over the approximate eastern two-thirds of the contiguous United States. We focus on conditions during two 6-h periods, 0000-0600 (Figs. 1a,b) and 1200-1800 UTC 30 April (Figs. 1c,d) when both the volume of air traffic and, accordingly, the number of turbulence reports are greatest. For the in situ EDR reports (Figs. 1a,c), recorded measurements with EDR $\leq 0.18$ are typically only downlinked at predetermined 15-20-min intervals to reduce transmission costs (Sharman et al. 2014). Thus, light turbulence and smooth air $(\mathrm{EDR} \approx 0.00)$ are underreported relative to the 1-min peak EDR values representing continuous MOG turbulence events. Light turbulence and smooth conditions, though most common, even on days with large amounts of MOG turbulence (like the current case), are also underreported in PIREPs (Figs. 1b,d).

Of the more than 1100 MOG turbulence reports during 0000-1800 UTC, more than 100 were of severe turbulence. For the in situ measurements, severe turbulence occurred intermittently over large horizontal distances during both analyzed 6-h periods (Figs. 1a,c) over the northern plains $\left(>40^{\circ} \mathrm{N}, 95^{\circ}-105^{\circ} \mathrm{W}\right)$. Severe turbulence was also recorded over the Mississippi-Ohio River Valley $\left(30^{\circ}-40^{\circ} \mathrm{N}, 85^{\circ}-90^{\circ} \mathrm{W}\right)$ regions on many flights during the second period between 1200 and 1800 UTC (Fig. 1c). This latter region of widespread severe turbulence (Fig. 2b) occurred mostly within deep convection (Fig. 2d) and is not analyzed in this study. Additional isolated severe turbulence, not indicated by the in situ reports, was evident from PIREPs over west Texas near $100^{\circ} \mathrm{W}$ during the earlier period (Fig. 1b).

Nearly all of the severe turbulence during this first period was closely associated with a deep midlatitude cyclone that moved slowly eastward from the southern Rockies (Fig. 2a) into the southern plains (Fig. 2b). Severe turbulence reports over the northern plains persisted throughout both periods near a strong UTLS jet stream north of the synoptic cyclone. The PIREPs of isolated severe turbulence in our first area of interest over northwestern Texas were located in the exit region of a UTLS jet near a band of shallow and relatively weak moist convection (Fig. 2c) that coincided with a midtropospheric front (Fig. 2a). Our second area of interest occurs the next morning and extends southwest-to-northeast from the col region north of the UTLS cutoff low into the entrance region of a synoptic jet streak (Fig. 2b). In the remainder of 
Aviation Turbulence Reports from Z $>24000 \mathrm{ft}(\mathrm{p}<400 \mathrm{hPa})$ on 30 April 2017
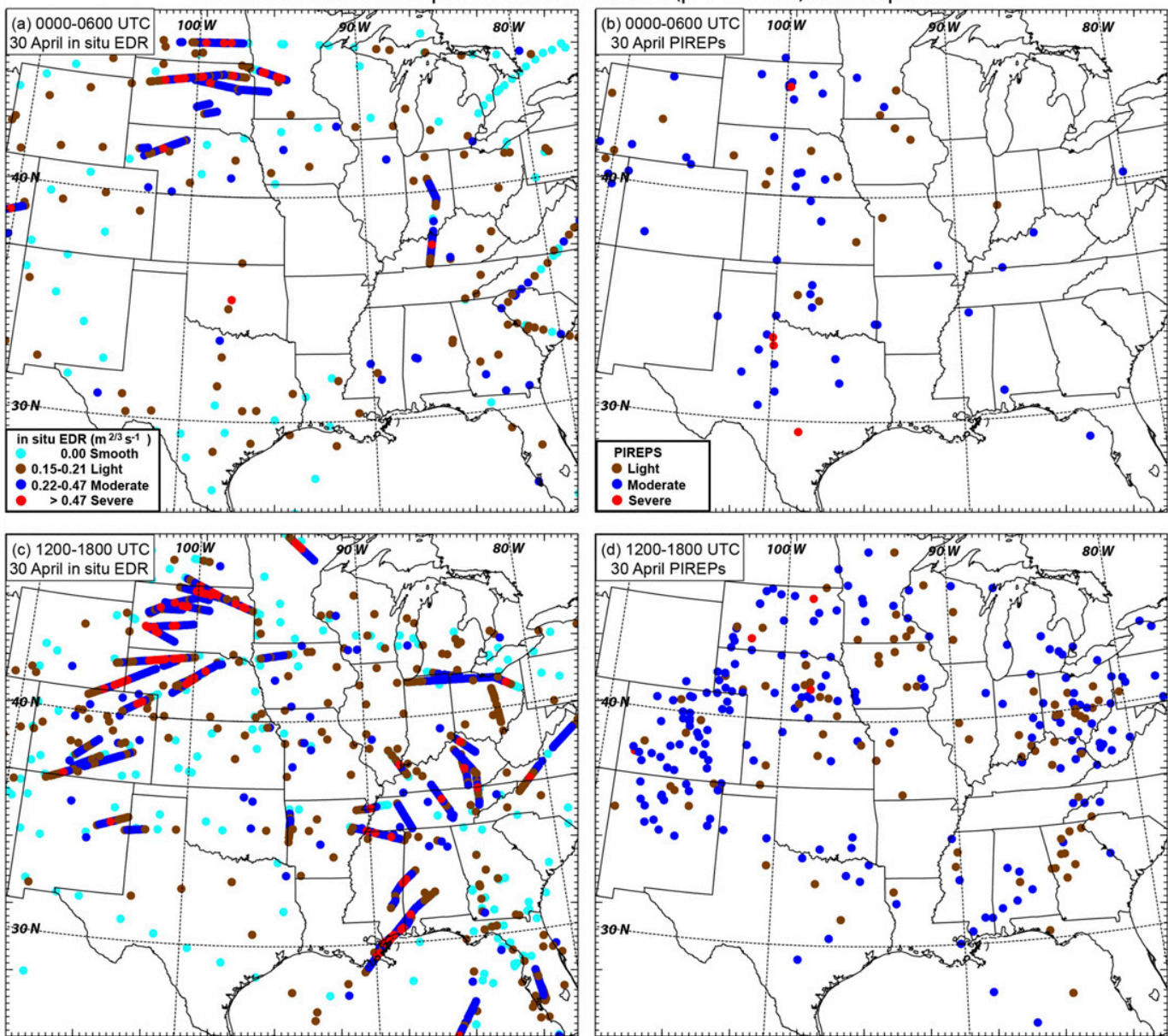

FIG. 1. Turbulence intensities above $24000 \mathrm{ft}$ MSL ( $~ 7.5 \mathrm{~km} \mathrm{MSL} ; \sim 400 \mathrm{hPa})$ from in situ EDR data on a subset of the commercial aviation fleet during (a) 0000-0600 and (c) 1200-1800 UTC 30 Apr 2017 and from PIREPs during (b) 0000-0600 and (d) 1200-1800 UTC 30 Apr 2017.

the paper we focus our analysis on both the isolated and more widespread severe turbulence located within these rectangular inset areas of Figs. $2 \mathrm{a}$ and $2 \mathrm{~b}$, respectively.

\section{Numerical model and experiment design}

Both the environment and mechanisms of severe turbulence are analyzed using output from numerical simulations with differing horizontal resolutions. These resolutions range from ones similar to those used in current operational prediction systems such as the HRRR model (e.g., Smith et al. 2008), which employs a horizontal grid spacing of $\Delta x \approx 3 \mathrm{~km}$, to much higher maximum horizontal resolutions in nested domains with horizontal spacing down to $\Delta x=370 \mathrm{~m}$.

\section{a. Numerical model and its initial and lateral boundary conditions}

We use version 3.8 of the Advanced Research version of the Weather Research and Forecasting (ARW-WRF) Model (Skamarock and Klemp 2008). Our model configuration has 82 vertical grid levels with a top at $26.3 \mathrm{~km}$. The vertical grid spacing increases linearly from 60 to $240 \mathrm{~m}$ in the lowest $2 \mathrm{~km}$. The $240-\mathrm{m}$ spacing remains approximately constant up to about $14 \mathrm{~km}$, and increases linearly to $1200 \mathrm{~m}$ at the top. A gravity-wave-absorbing layer (Klemp et al. 2008) is used in the upper $7 \mathrm{~km}$ of the model to mitigate spurious reflection of vertically propagating gravity waves off the model top.

The horizontal grid spacings of the domains with two-way interactive feedbacks used in all simulations are $\Delta x=10,3.3$, and $1.1 \mathrm{~km}$ (Fig. 3). The highest-resolution simulations also use domain d05, which is employed specifically to examine mechanisms responsible for the northern plains turbulence, and has a horizontal spacing of $370 \mathrm{~m}$.

The lateral boundary conditions for the outer domain are supplied by 6-h $1.0^{\circ}$ National Centers for Environmental Prediction (NCEP) Global Final (FNL) analyses. We initialize the ARW-WRF model using the concurrent FNL analysis at 1800 UTC 29 April 2017, and unless specified otherwise (Table 1) the model is integrated for $24 \mathrm{~h}$ until 1800 UTC 30 April 2017. 

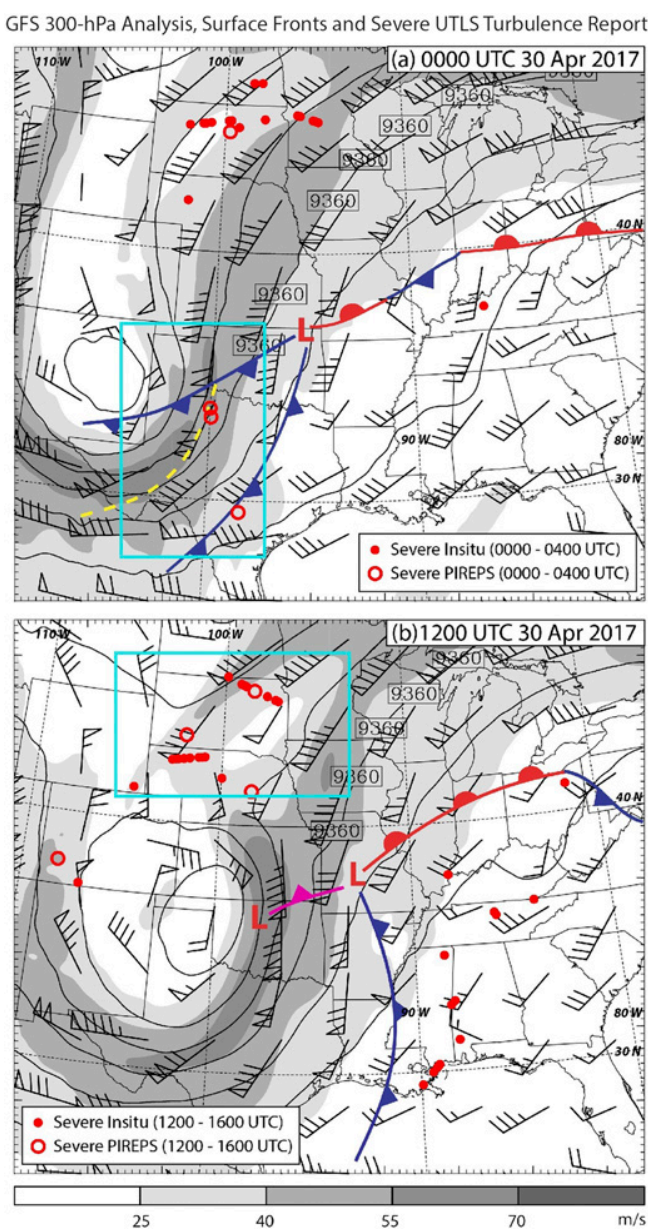

GOES-13 GVAR ch4 IR Satellite Brightness Temperature
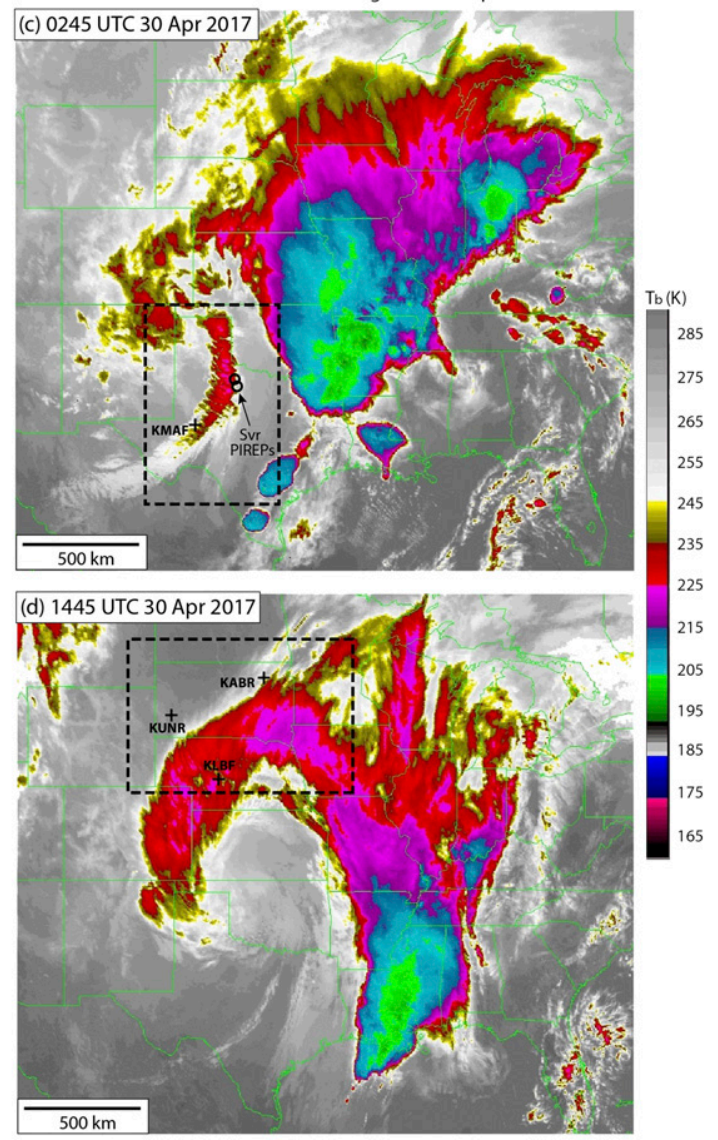

FIG. 2. Composite NCEP GFS analysis of meteorological conditions with severe turbulence reports (as in Figs. 1a,b) during the next $4 \mathrm{~h}$ superposed for (a) 0000 and (b) 1200 UTC 30 Apr 2017, and GOES-13 satellite brightness temperature for approximate corresponding times at (c) 0245 and (d) 1445 UTC 30 Apr 2017. The rectangular outlines in each panel indicate the regions of concentrated analysis of simulated turbulence events. Barbed symbols in (a) and (b) are horizontal winds, with half barb $=2.5 \mathrm{~m} \mathrm{~s}^{-1}$, full barb $=5 \mathrm{~m} \mathrm{~s}^{-1}$, and pennant $=25 \mathrm{~m} \mathrm{~s}^{-1}\left(1 \mathrm{~m} \mathrm{~s}^{-1}=1.94 \mathrm{kt}\right)$, and the geopotential contours are in 90-m intervals. The dashed yellow line in (a) indicates the position of the midtropospheric front, along which the narrow convective band of (c) occurs. The annotations in (c) and (d) indicate locations of NWS soundings at Midland, Texas (KMAF), Rapid City, South Dakota (KUNR), Aberdeen, South Dakota (KABR), and North Platte, Nebraska (KLBF), and turbulence events discussed later in the text.

\section{b. Physical parameterizations}

The Noah land surface model (Ek et al. 2003), which is coupled with ARW-WRF, provides the lower boundary condition for the atmospheric model. Each simulation uses the Rapid Radiative Transfer Model for Global Climate Models (RRTMG) longwave and shortwave radiation schemes (Mlawer et al. 1997; Iacono et al. 2008). All simulations, except those that do not include moist processes, use the Thompson et al. (2008) bulk microphysics parameterization in all domains, and the Tiedtke (1989) cumulus scheme is used in domain d01.

The planetary boundary layer (PBL) is parameterized using the Mellor-Yamada-Janjić (MYJ; Janjić 1994, 2001) scheme. This PBL scheme controls the vertical mixing between adjacent model layers throughout the entire model depth, and predicts the model subgrid TKE. The version used in the current simulations contains only local forcing in the vertical direction (i.e., no horizontal advection) of TKE from shear production $-\overline{w u}(\partial U / \partial z)-\overline{w v}(\partial V / \partial z)$, buoyancy production $\beta g \overline{w \theta_{l v}}$, and dissipation terms. In the buoyancy production term, $\theta_{l v}$ is the liquid potential temperature (Emanuel 1994) and $\beta$ is an empirical constant. In these production terms, the lowercase variables with overbars represent subgrid fluxes, which are parameterized in terms of vertical gradients of the resolved-scale (uppercase) variables. Horizontal mixing is determined using a Smagorinsky-type first-order closure (Skamarock and Klemp 2008).

\section{c. Simulations and sensitivity studies}

We present results from a control simulation (CTL), and a shorter-duration maximum horizontal resolution version, which uses d05 (Fig. 3), and is referred to as CTLHR. Since turbulence can occur in the absence of well-organized deep convection in 


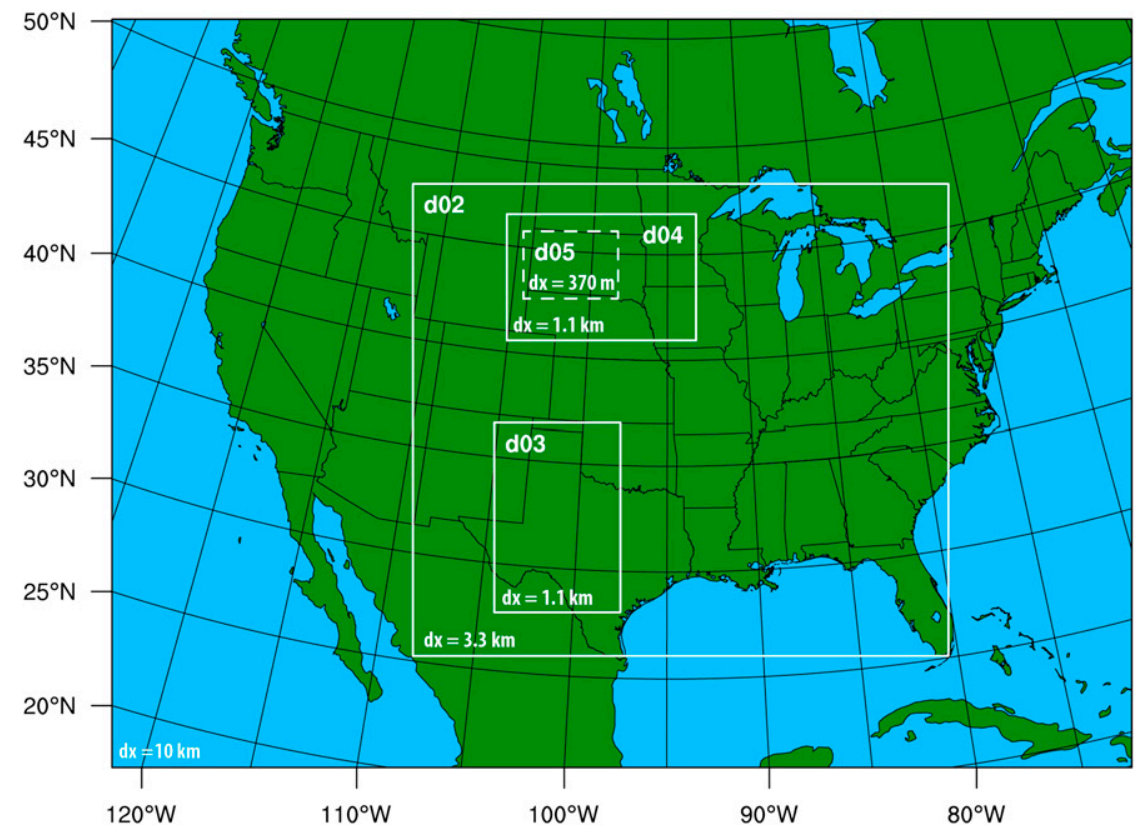

FIG. 3. Model domains for the simulations described in section 3 and analyzed in the remainder of the paper. The horizontal grid spacing is indicated within each domain.

synoptic weather systems, we examine the effects of clouds and deep convection by comparing CTL to an additional simulation DRY. DRY is configured in an identical fashion to CTL, except that all cloud microphysical processes are withheld. Table 1 lists key aspects of these simulations.

\section{Overview of simulations and comparison with observations}

CTL produces a synoptic-scale precipitation system with the most intense deep convection on its eastern flank. At 0000 UTC 30 April (Fig. 4a) there is also a secondary band of weaker simulated deep convection near KMAF. The KMAF sounding is located closest to the isolated severe turbulence near the east side of the observed convective band (cf. Fig. 2b), and has a broad peak in maximum wind speeds (Fig. 5a). Near the base of the synoptic trough, there is a strong simulated midtropospheric front (Fig. 6b), which is consistent with a secondary wind maximum located several kilometers beneath the higher maximum near the tropopause ( $\sim 9-10 \mathrm{~km} \mathrm{MSL}$ ) in both the observations and CTL (Fig. 5a).

The effect of convective UTLS outflow the following morning (1200 UTC 30 April) at Aberdeen, South Dakota (KABR)
(Fig. 4b), is indicated by a $\sim 20 \mathrm{~m} \mathrm{~s}^{-1}$ greater maximum wind speed in CTL relative to DRY (Fig. $5 b$ ), which is located $\sim 1 \mathrm{~km}$ above that in DRY. Both the altitude and structure of the jet in CTL are very similar to observations (Fig. 5b). Farther south, at North Platte, Nebraska (KBLF; Fig. 4b), the observed UTLS outflow jet is also well simulated in CTL (Fig. 5c). At Rapid City, South Dakota (KUNR), which is within the col region situated closer to the synoptic trough axis and near the extreme western edge of the UTLS convective outflow (Fig. 4b), maximum wind speeds are much weaker (Fig. 5d) than at KABR (Fig. 5b). At 1200 UTC, the UTLS outflow jet near $11 \mathrm{~km}$ MSL at KUNR is positioned only $\sim 250 \mathrm{~m}$ below the observed jet, but is overestimated by $7 \mathrm{~m} \mathrm{~s}^{-1}$ in CTL (Fig. 5d). At both KBLF (Fig. 5c) and KUNR (Fig. 5d), DRY lacks a significant UTLS jet altogether.

Although slightly stronger than observed, the convective band (Fig. 6a) occurring in the environment of the evening turbulence over west Texas (Fig. 2a) is well simulated in d03 of CTL (Fig. 6b). This convection is strongly forced along the intensifying midtropospheric front (Fig. 6b) and extends upward to the local tropopause between 350 and $275 \mathrm{hPa}$ in CTL (Fig. 7). However, it occurs significantly west of the surface

TABLE 1. List of simulations discussed in the paper.

\begin{tabular}{llll}
\hline \hline Simulation & \multicolumn{1}{c}{ Horizontal grid spacings } & Microphysics scheme & \multicolumn{1}{c}{ Initialization time } \\
\hline CTL & $\Delta x=10,3.3$, and $1.1 \mathrm{~km}$ & Thompson et al. (2008) & 1800 UTC 29 Apr 2017 \\
CTLHR & $\Delta x=10,3.3,1.1$, and $0.37 \mathrm{~km}$ & Thompson et al. (2008) & 1800 UTC 29 Apr 2017, d05 with $\Delta x=0.37 \mathrm{~km}$ started at \\
& & & 1200 UTC 30 Apr 2017 \\
DRY & $\Delta x=10,3.3$, and $1.1 \mathrm{~km}$ & None & 1800 UTC 29 Apr 2017 \\
DRYHR & $\Delta x=10,3.3,1.1$, and $0.37 \mathrm{~km}$ & None & 1800 UTC 29 Apr 2017, d05 with $\Delta x=0.37 \mathrm{~km} \mathrm{started} \mathrm{at}$ \\
& & & 1200 UTC 30 Apr 2017 \\
\hline
\end{tabular}


MREF and 11-km MSL Winds in d02 in CTL
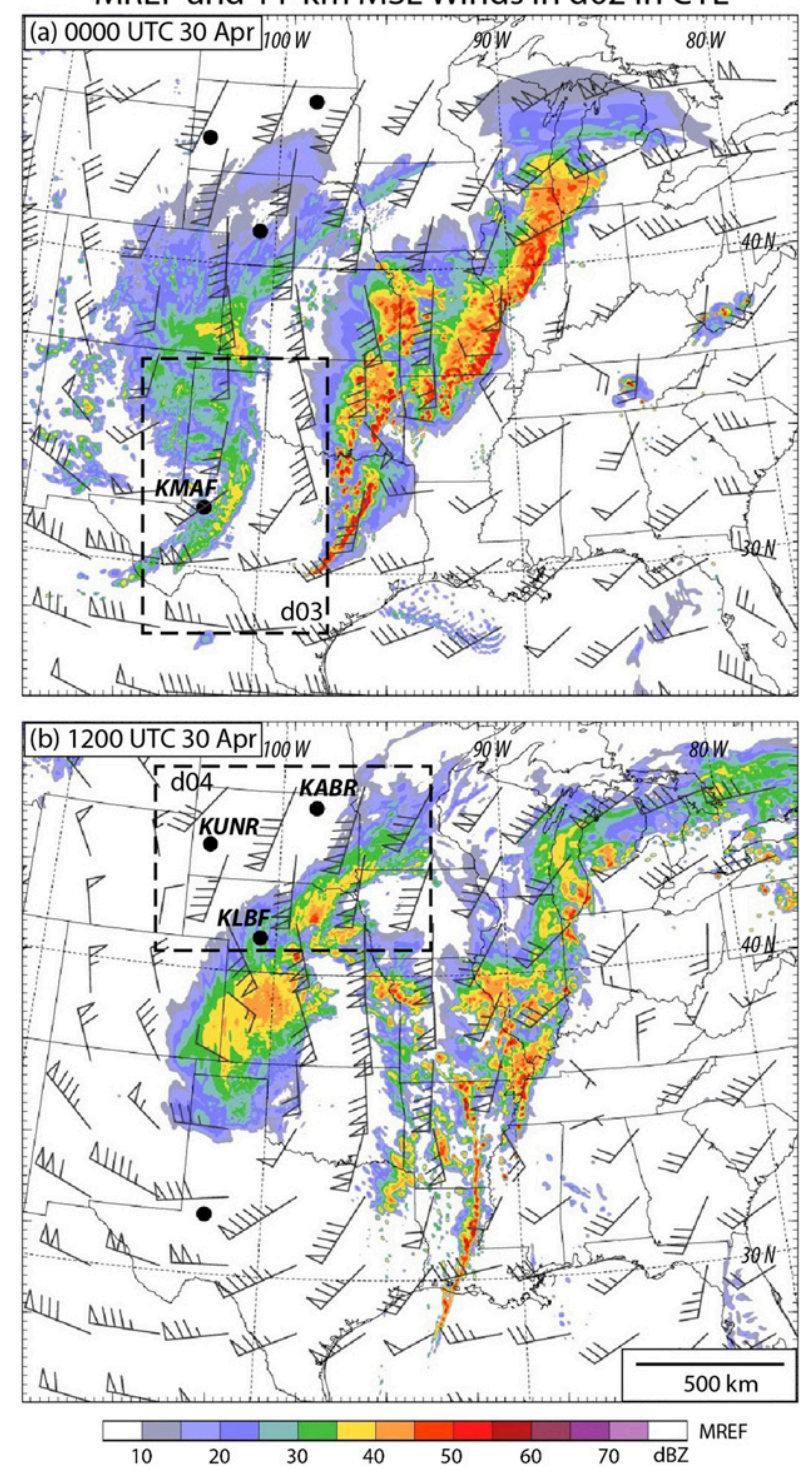

FIG. 4. Horizontal winds at $11 \mathrm{~km}$ MSL with model-derived maximum reflectivity in vertical column (MREF) for domain $\mathrm{d} 02$ (Fig. 3) for simulation CTL at (a) 0000 and (b) 1200 UTC 30 Apr 2017. The annotations indicate NWS sounding locations where wind speed profiles in the higher-resolution model domains d03 and d04 (dash-outlined rectangles) are plotted in Fig. 5.

cold front and both its moist updrafts $\left(w_{\max } \leq 2-4 \mathrm{~m} \mathrm{~s}^{-1}\right.$, not shown) and maximum reflectivity (Fig. 6b) are relatively weak as a result of small maximum convective available potential energy (MUCAPE) in its inflow (Fig. 6c).

Both the location and orientation of the simulated cloud band (Fig. 7a) are similar to observations (dashed rectangle in Fig. 2c). In this region, the model-parameterized TKE is relatively isolated and is located near cloud top but a few kilometers outside of cloud (Fig. 7b) and above the eastern edge of the broader cloud band (Fig. 7a). The location of the 0300 UTC $275-\mathrm{hPa}$ model-parameterized TKE is only

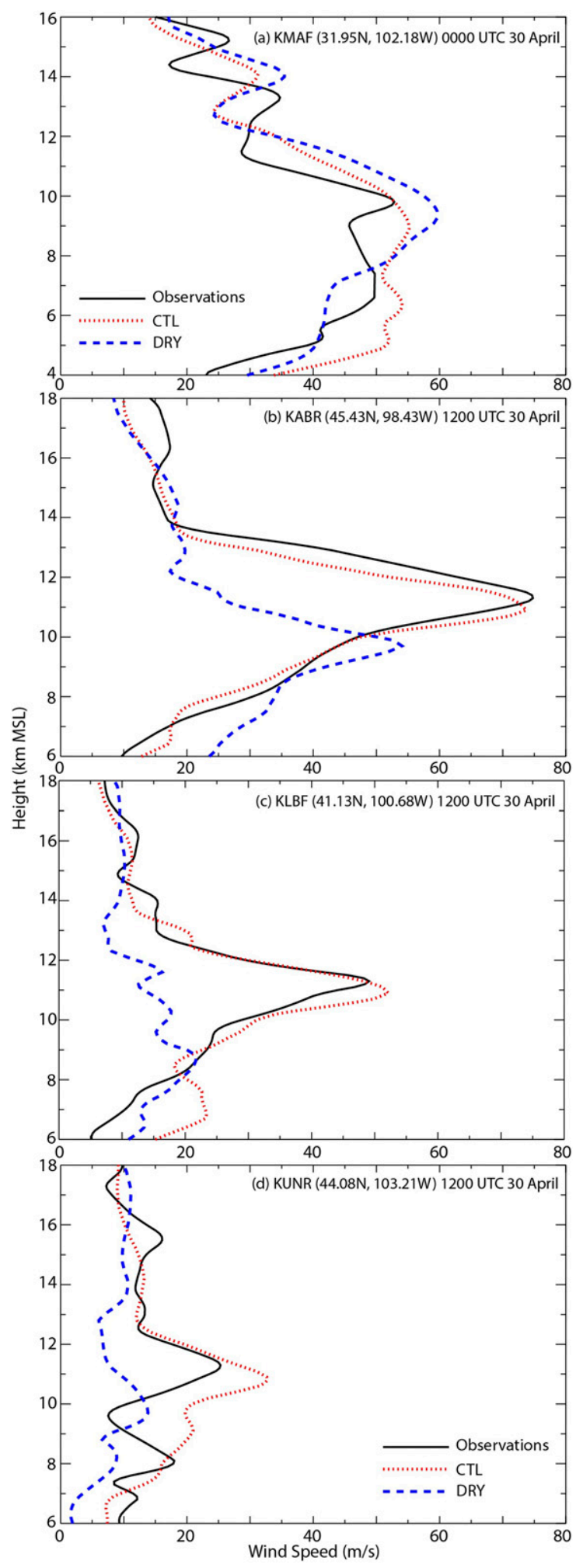

FIG. 5. Observed and simulated wind speed profiles for NWS sounding locations at (a) Midland (KMAF) in domain d03 at 0000 UTC 30 Apr 2017 and (b) Aberdeen (KABR), (c) North Platte (KLBF), and (d) Rapid City (KUNR), each located in domain d04 at 1200 UTC 30 Apr 2017. The sounding locations and model domains in which they reside are shown in Fig. 4. 

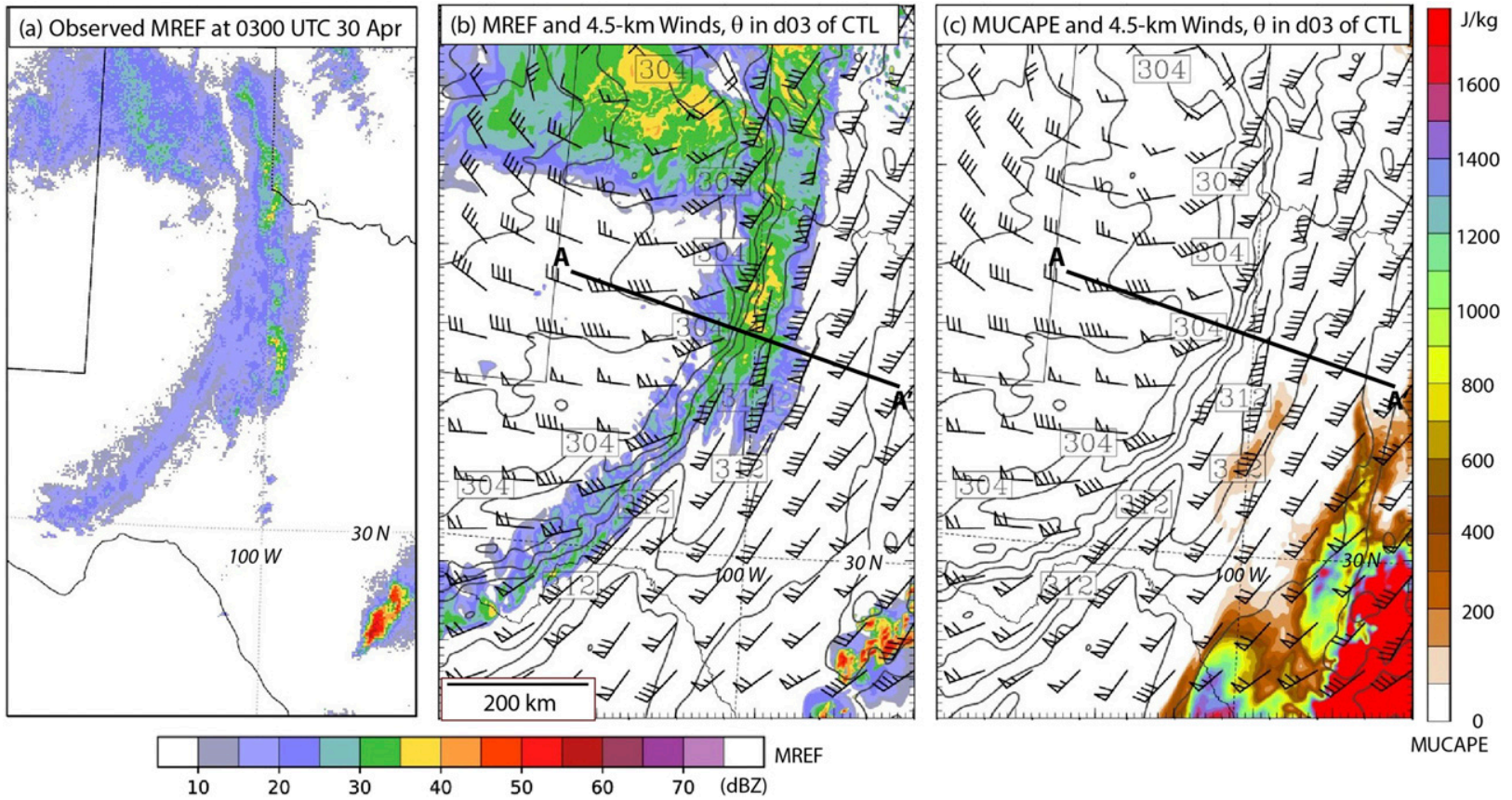

FIG. 6. (a) Observed maximum radar reflectivity in a vertical column over the approximate area of model domain d03 at 0300 UTC 30 Apr 2017, (b) simulated maximum radar reflectivity in a vertical column and 4.5-km MSL horizontal winds (barbed symbols as in Fig. 2) and potential temperature (2-K contour intervals), and (c) simulated convective available potential energy for the parcel with largest equivalent potential temperature in a vertical column (MUCAPE; color shading) and 4.5-km MSL winds and potential temperature [as in (b)] for domain d03 of simulation CTL at 0300 UTC 30 Apr 2017. The transect AA $^{\prime}$ in (b) and (c) locates the vertical cross sections displayed later in Fig. 9.

25-50 km northeast of the severe PIREPs (Fig. 7b), which were from two different aircraft and occurred slightly earlier at 0241 and 0247 UTC. These severe PIREPs were also located near the east edge of the cloud band (Fig. 2c) and had altitudes of 32 and $34 \mathrm{kft}(\sim 9.8$ and $\sim 10.4 \mathrm{~km} ; \sim 275$ and $\sim 250 \mathrm{hPa}$ ). The three nearby PIREPs of moderate turbulence (Fig. 7b) occurred between 0225 and 0347 UTC and were from similar or slightly higher altitudes $(32-36 \mathrm{kft}$, or $\sim 9.8-11.0 \mathrm{~km}$ ). Like the severe PIREPs in the observations (Fig. 2a), the model-parameterized TKE occurred within the exit region of the UTLS jet (Fig. 7b).

Enhanced model-parameterized TKE in d04 of CTL over the northern plains the following morning at 1430 UTC (Fig. 8) is more widespread, which is consistent with the greater number and horizontal extent of MOG turbulence reports for the surrounding two hours, compared to situation in the west Texas region the evening before (Fig. 7). One area of widespread enhanced TKE occurs at $300 \mathrm{hPa}$ along the east side of the UTLS trough axis a few hundred $\mathrm{km}$ northwest of the edge of the simulated clouds (Fig. 8a). This modelparameterized TKE is supported by several PIREPs of moderate turbulence having similar location and orientation along but outside of the simulated northwestern cloud edge (Fig. 8a). There is also a single in situ observation of severe turbulence near KUNR (Fig. 8b) from 1425 UTC occurring slightly above at $34 \mathrm{kft}(\sim 10.4 \mathrm{~km} ; \sim 250 \mathrm{hPa})$. However, there are also numerous PIREPs of moderate turbulence within the simulated cloud (Fig. 8a) that appear unassociated with enhanced model-parameterized TKE, which could be related to model resolution or deficiencies in the microphysics or other parameterizations.

A second area of widespread model-parameterized TKE occurs at $200 \mathrm{hPa}$ (Fig. 8b) and is located above the simulated 300-hPa cloud edge (Fig. 8a). There are two flights with lengthy in situ observations of MOG turbulence near the enhanced model-parameterized TKE (Fig. 8b). One is a westbound flight with MOG turbulence from 1408 to 1430 UTC located near the south edge of the 1430 UTC simulated widespread TKE region. Another is an eastbound flight with MOG turbulence from 1503 to 1526 UTC near the center of this TKE region. There was also a single PIREP of severe turbulence near KABR reported at 1530 UTC (Fig. 8b). The simulated region of widespread 200-hPa TKE in d04 of CTL shifts northeastward with time (not shown), presumably in response to variations in UTLS outflow from deep convection located to its south (cf. Figs. 4b and 5b), and is consistent with the available turbulence observations.

\section{Mechanisms of turbulence}

\section{a. Evening turbulence in west Texas (0000-0400 UTC 30 April)}

The previous section documented isolated severe turbulence occurring in the vicinity of the midtropospheric front (Fig. 2a) 


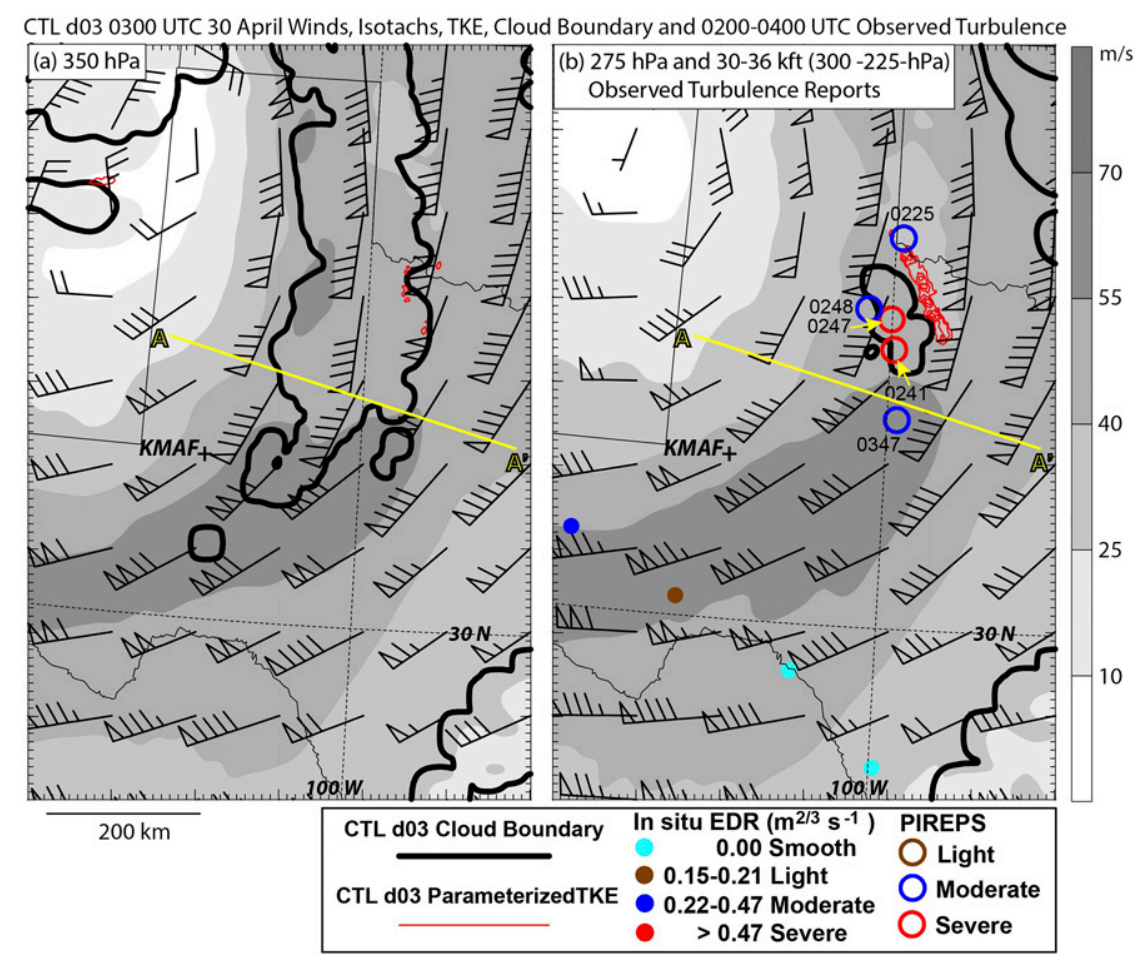

FIG. 7. Simulated horizontal winds (barbed symbols as in Fig. 2), model parameterized turbulence kinetic energy (red contours, with $1 \mathrm{~m}^{2} \mathrm{~s}^{-2}$ contour intervals), isotachs (gray shading), and cloud boundary (single thick black contour, with total cloud condensate $\geq$ $\left.0.005 \mathrm{~g} \mathrm{~kg}^{-1}\right)$ in domain d03 of CTL at 0300 UTC $30 \mathrm{Apr} 2017(t=9 \mathrm{~h})$ for (a) 350 and (b) $275 \mathrm{hPa}$. The superposed observed turbulence reports (see lower legend) are at the indicated times and heights/pressures. The annotations next to the PIREP locations in (b) indicate the times (UTC 30 Apr 2017) of selected turbulence reports. The annotated location KMAF (Midland) denotes the location of 0000 UTC 30 Apr wind speed profiles displayed in Fig. 5a. The transect $\mathrm{AA}^{\prime}$ in both panels indicates the horizontal position of the vertical cross sections in $\mathrm{d} 03$ of the CTL (Figs. 9a,b) and DRY (Figs. 9c,d) simulations described later.

and associated weak convective band in west Texas (Figs. 2c and 6a). A vertical cross section along transect $\mathrm{AA}^{\prime}$ in $\mathrm{d} 03$ through the simulated midtropospheric front (Fig. 6b) shows cloud condensate extending upward from the frontal zone to a lowered tropopause located at $\sim 9 \mathrm{~km}$ MSL in CTL (Fig. 9a). Model-parameterized TKE occurs within the sloping frontal zone near cloud base and is associated with strong vertical shear in the plane of the vertical cross section (Fig. 9b).

Of potentially greater direct relevance to the turbulence occurring at commercial aviation cruising altitudes (i.e., $z \geq 8.5 \mathrm{~km} \mathrm{MSL}$ ) is the wave activity located in the lower stratosphere above the moist convection (Fig. 9a). Modelparameterized TKE is present where wave breaking (i.e., $\partial \theta / \partial z<0$ ) occurs in CTL (Fig. 9a). The wave breaking and lower-stratospheric TKE above the moist convection are located in layers of strong vertical shear (Fig. 9b) and low wind speed. Though the breaking in CTL is situated above deep convection, its similar horizontal location $(x=320-380)$ above the midtropospheric front in DRY (Fig. 9c) is noteworthy. The resulting TKE in DRY is less widespread and intense, presumably because the UTLS wind shear is weaker in
DRY (Fig. 9d) compared to CTL (Fig. 9b). The breaking in this region in both simulations is suggestive of a critical level near $U$ $\sim 10 \mathrm{~m} \mathrm{~s}^{-1}$, defined as where the horizontal phase speed of the waves nearly equals that of the horizontal flow $U$ in that direction. We examine this hypothesis in more detail later in this section.

The mesoscale lower-stratospheric waves are evident at $150 \mathrm{hPa}$ within d02 of CTL (Fig. 10). Though the horizontal wavelength, $\lambda$, varies somewhat across $\mathrm{d} 02, \lambda \approx 100 \mathrm{~km}$ near the location of simulated wave breaking, which is indicated by the star symbol along transect $\mathrm{BB}^{\prime}$ (Fig. 10b) and is shown in the vertical cross section of Fig. $11 \mathrm{c} .^{2}$ The $1 / 4$ wavelength phase lag between vertical velocity and potential temperature perturbations (Fig. 10) confirms that these features are gravity waves. At the onset of their breaking (02000300 UTC 30 April), the mesoscale gravity waves have

\footnotetext{
${ }^{2}$ The star symbol in Fig. 10 also approximates the horizontal location of the 0300 UTC maximum 200-hPa TKE in d03 (Fig. 7b).
} 
CTL d04 1430 UTC 30 April Winds, Isotachs, TKE, and Cloud Boundary and $1330-1530$ UTC 30 April Observed Turbulence
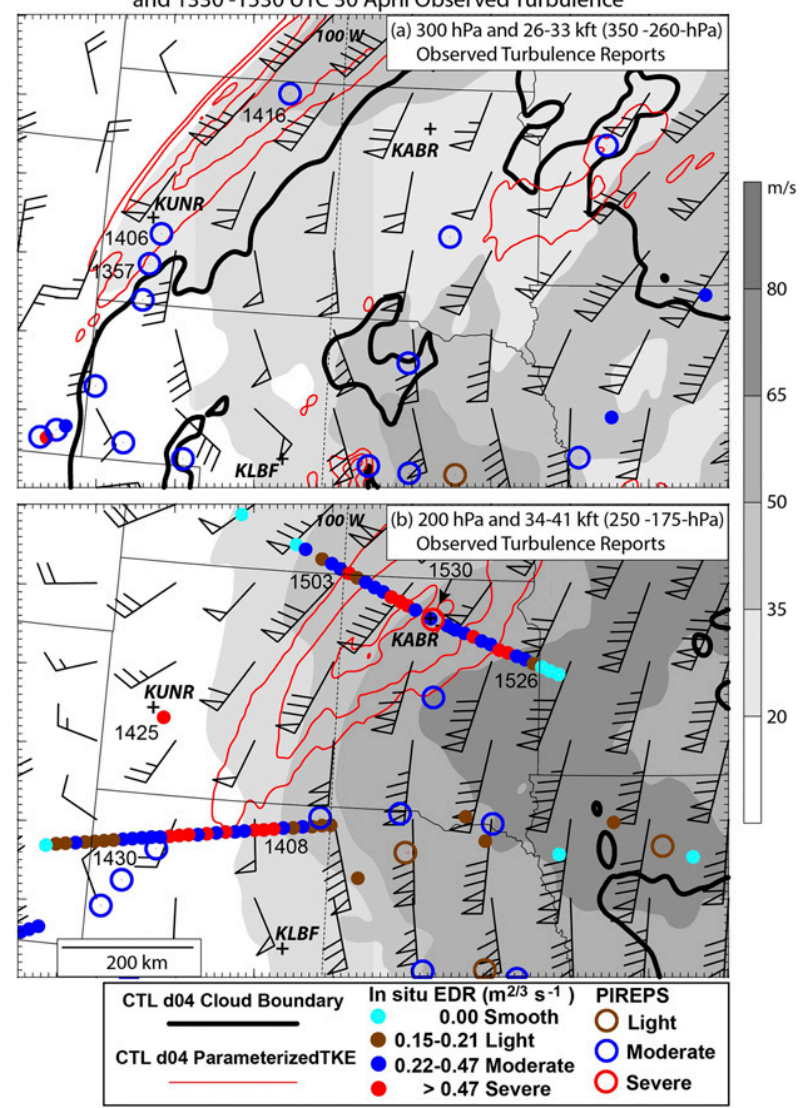

FIG. 8. As in Fig. 7, but for domain d04 of CTL at 1430 UTC 30 Apr 2017 ( $t=20.5 \mathrm{~h}$ ) for (a) 300 and (b) $200 \mathrm{hPa}$. The superposed observed turbulence reports (see lower legend) are at the indicated times and heights/pressures. The annotations next to the plotted symbols indicate the times (UTC 30 Apr 2017) of selected turbulence reports. The annotated locations KABR (Aberdeen); KLBF (North Platte); and KUNR (Rapid City) denote the location of 1200 UTC 30 Apr wind speed profiles displayed in Figs. 5b-d, respectively.

horizontal phase velocities of about $5-7 \mathrm{~m} \mathrm{~s}^{-1}$ along transect BB' (Figs. 10a,b).

These waves have multiple possible sources, which have not been unambiguously determined. Because this region is not located near significant terrain, topographic generation is unlikely. However, the waves resemble the inertia-gravity waves discussed by Zhang (2004), which similarly occurred in the exit region of a UTLS jet streak (Fig. 10) and had reported horizontal (100-200 km) and vertical $(2.5 \mathrm{~km})$ wavelengths similar to those simulated in the current case. Following the conceptual model developed by Uccellini and Koch (1987) and Koch and Dorian (1988), the jet exit region is widely accepted as a preferred location for inertia-gravity wave activity. Zhang (2004) attributed the origin of vertically propagating mesoscale waves to nonlinear balance adjustment occurring in the UTLS jet exit region.

Earlier, at 2230 UTC 29 April, there is widespread lowerstratospheric wave activity along transect $\mathrm{BB}^{\prime}$ in $\mathrm{d} 02$ of CTL
(Fig. 11a). This includes high-amplitude waves of shorter horizontal wavelengths that are excited by the moist convection impinging on the locally lower tropopause located above the midtropospheric front (dashed wave fronts in Fig. 11a), and mesoscale waves with larger westward tilt located farther east (solid wave fronts in Fig. 11a). These small-amplitude mesoscale waves are also evident in the same locations of DRY at 2230 UTC (solid wave fronts in Fig. 11b).

At this earlier time DRY also contains eastward tilting tropospheric waves emanating from the intensifying midtropospheric frontal zone near $x \approx 200-400 \mathrm{~km}$ (Fig. 11b), which are similar to those in CTL (Fig. 11a). These similarities between CTL and DRY suggest that the mesoscale waves, which eventually break and are associated with modelparameterized TKE (Figs. 11c,d), may be strongly influenced by dry dynamical processes including midtropospheric frontogenesis and balance adjustment in the UTLS jet exit region.

However, substantial differences in the structure of these longer mesoscale gravity waves and their associated TKE develop between CTL and DRY during the next several hours. For instance, in CTL there is wave breaking with large TKE occurring from 9 to $11 \mathrm{~km}$ MSL above and immediately east of moist convection, which are located in the vicinity of nearly simultaneous severe PIREPs (Fig. 11c). In contrast, the lowerstratospheric wave breaking in DRY at 0300 UTC is confined to altitudes above $12 \mathrm{~km}$ MSL (Fig. 11d). The shorter wavelengths excited by moist convection (Figs. 11a,c) along the midtropospheric front (Fig. 6b) impinging on the locally lowered tropopause (e.g., Fovell et al. 1992; Lane et al. 2003) may interfere constructively with the slower-moving $\left(c \approx 5-7 \mathrm{~m} \mathrm{~s}^{-1}\right)$ longer waves, which amplify and break at lower altitudes in CTL, and thus may offer a partial explanation for these differences between CTL and DRY. However, a second and seemingly more important factor is related to modification of the environment at altitudes immediately above subsequent wave breaking as the eastward-moving moist convection approaches the trailing anvil of the stronger and deeper moist convection located farther east along the surface cold front (Fig. 11c).

Fig. 12a reveals dramatic 6-h reductions in the flow strength in the direction of horizontal phase velocity (i.e., along $\mathrm{BB}^{\prime}$ in Fig. 10) that are maximized near $11.5 \mathrm{~km} \mathrm{MSL}$ at the location of subsequent wave breaking in CTL. The $c \approx 5-7 \mathrm{~m} \mathrm{~s}^{-1}$ horizontal phase speeds of the mesoscale waves estimated from Figs. 10a and $10 \mathrm{~b}$ result in critical levels where $U=c$ at 11.1 and $11.9 \mathrm{~km}$ MSL in the 0200 UTC vertical profile (Fig. 12a). This is consistent with wave breaking at 0300 UTC occurring for a 3-km depth along BB' (Fig. 11c) beneath the critical levels.

The horizontal location of the wave breaking event in CTL occurs where 6-h changes in the 11.5 -km MSL environmental wind magnitude in the direction of horizontal phase propagation along $\mathrm{BB}^{\prime}$ is maximized (Fig. 12b). The instantaneous 0200 UTC (CTL - DRY) wind difference field implied that these changes (Fig. 12a) are dominated by UTLS outflow from the deeper moist convection reaching the location of the shallower convection and subsequent wave breaking indicated by the purple dot in Fig. 12b.

In summary, the foregoing analysis suggests that mesoscale gravity waves excited by dry dynamical processes occurring in 

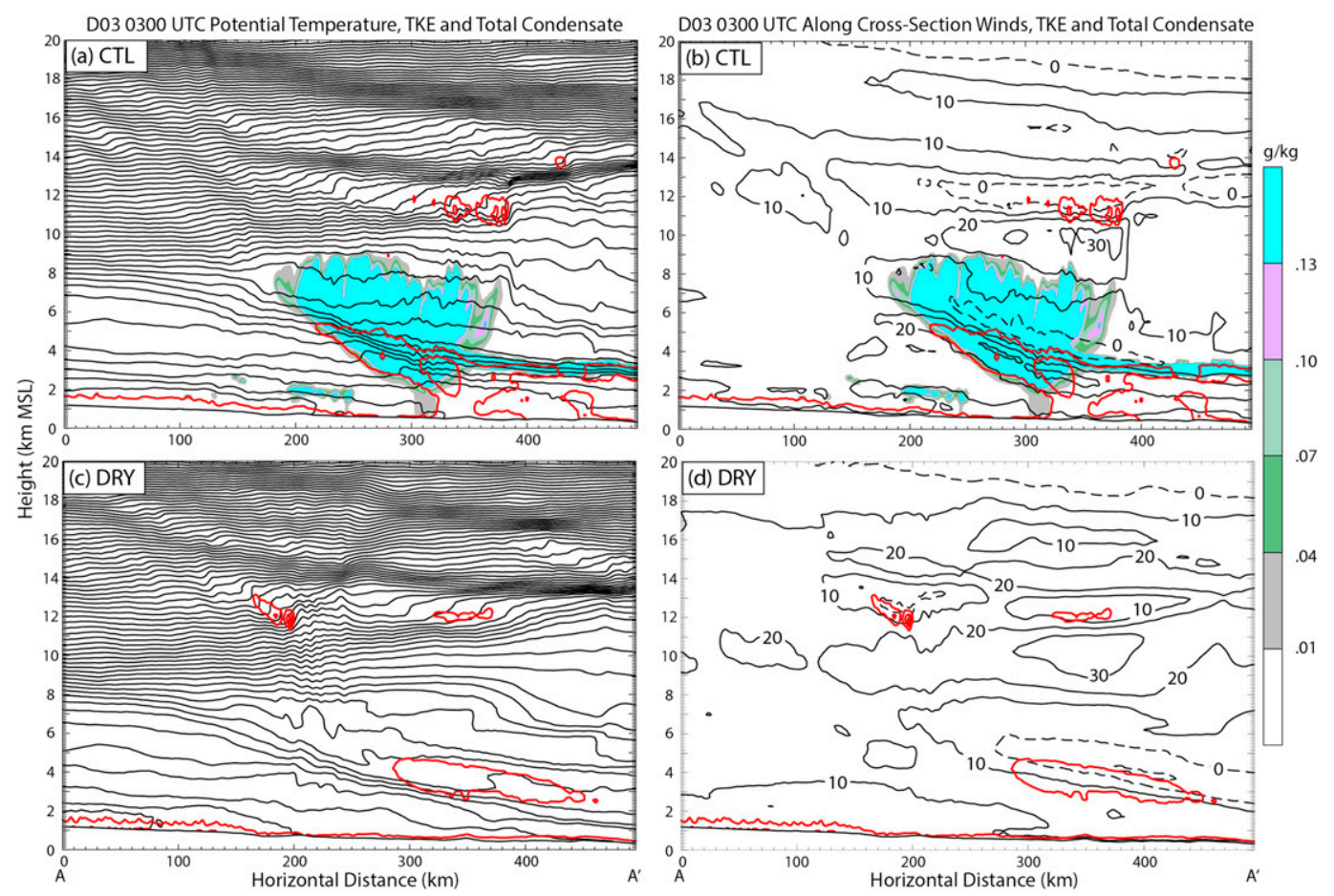

FIG. 9. Domain d03 turbulence kinetic energy (red contours, with $1 \mathrm{~m}^{2} \mathrm{~s}^{-2}$ intervals), total condensate (color shading), (left) potential temperature (black contours, with 3-K intervals), and (right) horizontal wind along the cross section (black contours, with $10 \mathrm{~m} \mathrm{~s}^{-1}$ intervals and negative values dashed) for the (a),(b) CTL and (c),(d) DRY simulations along transect AA' of Figs. 6b and 6c at 0300 UTC 30 Apr $2017(t=9 \mathrm{~h})$.

the exit region of upper-tropospheric jet/front system break and produce turbulence underneath a critical level influenced by UTLS outflow from distant deep convection. The collocation of these mechanisms in a region that may also be locally influenced by weaker moist convection is consistent with the relatively isolated model-parameterized TKE and locally concentrated observations of moderate and severe turbulence (Fig. 7b).

\section{b. Daytime turbulence in the northern Great Plains (1200-1600 UTC 30 April)}

The contribution to total horizontal wind speed from UTLS convective outflow in $\mathrm{d} 02$ of CTL at 1400 UTC the following morning over the northern plains is larger and more widespread than earlier in west Texas, with maximum increases relative to DRY values exceeding $45 \mathrm{~m} \mathrm{~s}^{-1}$ near KABR (Fig. 13a). Vertical cross section WE taken through this strongly affected region in CTL indicates more widespread model-parameterized TKE (Fig. 13b) than for the previous severe turbulence episode over west Texas (cf. Fig. 11c).

In vertical cross section WE there are three TKE centers, two of which occur outside of cloud (Fig. 13b). The most widespread region (feature $\mathrm{A}$ ), which also has the largest TKE values, is located from $x \approx 400$ to $800 \mathrm{~km}$ and occurs above the western edge of the UTLS jet, and is centered $\sim 1 \mathrm{~km}$ above cloud. The second region (feature B), located between $x=$ 300 and $x=400 \mathrm{~km}$, is west of the widespread cloudiness and is centered at lower altitudes ( $z=8.5-9.5 \mathrm{~km} \mathrm{MSL})$ within the tropopause fold delineated by the 2-PV unit surface.
The vertical shear conducive to model-parameterized TKE within the tropopause fold arises from the westward extension of outflow-enhanced southerly flow normal to the vertical cross section overlying the northerly flow west of the synoptic trough axis at lower altitudes in CTL (Fig. 13b). Slow eastward movement of the synoptic trough axis is accompanied by an anticyclonic rotation of the winds at $8 \mathrm{~km}$ MSL at the dotted locations in CTL between 1200 and 1400 UTC 30 April (blue wind barbs in Figs. 14a and 14b). The 8-km MSL wind shift is overlaid by concurrent local intensification of outflow at $10 \mathrm{~km}$ (red barbs in Figs. 14a and 14b) from the precipitation system to the south. This evolution enhances the vertical shear over a narrow region extending northeastward from KUNR (Fig. 14b), in which TKE feature B (Fig. 13b) develops. Some TKE is also produced both above and west of a weaker UTLS jet in DRY (Fig. 13c), but it is considerably weaker and less extensive than in CTL (Fig. 13b).

The strong vertical shears in simulated turbulence regions A and B of CTL by 1400 UTC suggest KH instability as a possible mechanism for the simulated (and observed) turbulence (e.g., Ludlam 1967; Klostermeyer and Rüster 1980). We investigate this possibility in the remainder of this section by analyzing environmental conditions and turbulence mechanisms in d05 (dashed inset of Fig. 13a), which is initialized $2 \mathrm{~h}$ earlier at 1200 UTC 30 April 2017 in the high-resolution $(\Delta x=370 \mathrm{~m})$ simulation CTLHR (Table 1).

A widespread region of patchy wavelike vertical velocity perturbations, oriented normal to the UTLS vertical shear 
CTL d02 150-hPa Vertical Velocity, Potential Temperature, and Cloud
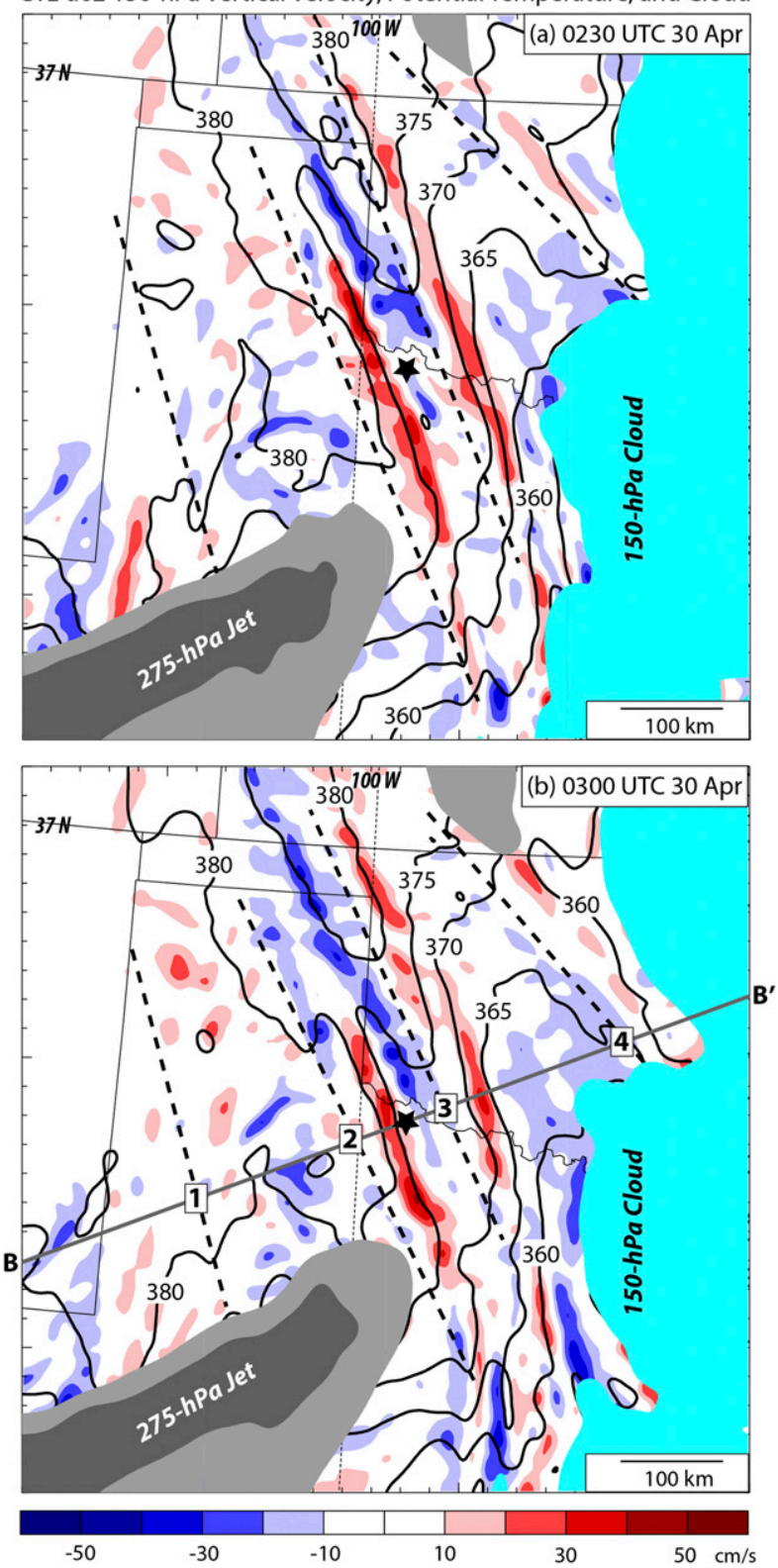

FIG. 10. Vertical velocity (blue and red color shading), potential temperature (black contours, with 5 -K contour intervals), and cloud region (cloud condensate $\geq 0.005 \mathrm{~g} \mathrm{~kg}^{-1}$; cyan shading) in the lower stratosphere at $150 \mathrm{hPa}(\sim 44 \mathrm{kft}$ or $13.5 \mathrm{~km} \mathrm{MSL}$ ) for a portion of domain d02 of CTL at (a) 0230 UTC $(t=8.5 \mathrm{~h})$ and (b) $0300 \mathrm{UTC}(t=9 \mathrm{~h}) 30 \mathrm{Apr} 2017$. The gray shading in each part indicates the horizontal position of the 275-hPa upper-tropospheric jet streak (55 and $60 \mathrm{~m} \mathrm{~s}^{-1}$ isotachs are shaded), and the thick dashed lines indicate phase lines (wave fronts) of the mesoscale waves discussed in the text. The transect $\mathrm{BB}^{\prime}$ indicates the location of the vertical cross sections displayed in Fig. 11, and the star symbol locates the position of simulated mesoscale wave breaking at the altitude and approximate horizontal location of the observed isolated severe turbulence. The annotated numbers signify the lower-stratospheric long waves displayed in the $\mathrm{BB}^{\prime}$ vertical cross section of Fig. 11. outside of the simulated cloud boundary (Fig. 15a), develops rapidly after initialization of d05 in CTLHR. The vertical shear in which these vertical velocity perturbations occur is located above the UTLS outflow jet, and in the region corresponding to that of the model-parameterized TKE feature A in d02 of CTL (Fig. 13b). Wavelike vertical velocity perturbations oriented normal to the vertical shear in CTLHR also develop a few hours later after vertical shear intensifies in the tropopause fold at lower altitudes west of the cloud boundary (Fig. 15b). This region in $\mathrm{d} 05$ corresponds to that containing modelparameterized TKE feature B in d02 of CTL (Fig. 13b).

Vertical cross sections oriented normal to the vertical velocity perturbations and along the vertical shear in Figs. 15a and $15 \mathrm{~b}$ indicate overturning isentropes at $\sim 12 \mathrm{~km}$ (Fig. 16a) and $\sim 9 \mathrm{~km}$ (Fig. 16b) MSL, respectively. These potential temperature features that resemble KH billows (Figs. 16a,b) originate from within layers of precursor gradient Richardson number $\mathrm{Ri}=N^{2} / S^{2}<0.25$ (Figs. 17a,c), where $N^{2}=(g / \theta)(\partial \theta / \partial z)$ is the static stability and $S^{2}=\|\partial \mathbf{V} / \partial z\|^{2}$ is the square of the vertical shear magnitude. These layers of $\mathrm{Ri}<0.25$ may be conducive to two-dimensional KH instability (Miles 1986) and are found both above the convectively enhanced UTLS jet (Fig. 17a) and beneath the weaker UTLS jet (Fig. 17c) farther west in the region of the tropopause fold. Ri becomes $<0$ within these layers at both $\sim 12 \mathrm{~km} \mathrm{MSL} \mathrm{(Fig.} \mathrm{16a)} \mathrm{and} \mathrm{farther} \mathrm{west} \mathrm{at}$ $\sim 9 \mathrm{~km}$ MSL (Fig. 16b) at the onset of overturning.

The horizontal wavelengths of these KH-like billows vary from $\lambda \approx 5 \mathrm{~km}$ in cross section SE-NW (Fig. 16a) to $\lambda \approx 9-10 \mathrm{~km}$ in cross section SW-NE (Fig. 16b). Since KH-billow wavelengths are often shorter (e.g., Browning 1971; Wroblewski et al. 2007; Geerts and Miao 2010; Grasmick and Geerts 2020), there is a need to determine whether the simulated $\mathrm{KH}$-like billows are resolved at the 370-m horizontal grid spacing used in simulation CTLHR. According to Scorer (1969), the longest wavelength for two-dimensional KH instability in linear shear is

$$
\lambda_{\max }=\pi \Delta z / \mathrm{Ri},
$$

where $\Delta z$ is the depth of the unstable layer. Estimating the average depth of the $\mathrm{Ri}<0.25$ layer above the jet in cross section SE-NW (Fig. 17a) as $700 \mathrm{~m}$ and taking $\mathrm{Ri}=0.25$ together yield $\lambda_{\text {max }} \approx 17.5 \mathrm{~km}$. $^{3}$ Estimating the average depth of the $\mathrm{Ri}<0.25$ layer beneath the jet in the southwestern half of cross section SW-NE ( $x=0-38 \mathrm{~km}$ in Fig. $17 \mathrm{~b})$, where wave breaking has not yet started, to be $1 \mathrm{~km}$ and similarly taking $\mathrm{Ri}=0.25$ yields $\lambda_{\text {max }} \approx 25 \mathrm{~km}$. These wavelengths are approximately 2.5 times as large as simulated horizontal wavelengths of 5 and $9-10 \mathrm{~km}$ between overturning isentropes in Figs. 16a and $16 \mathrm{~b}$, respectively. Furthermore, these simulated wavelengths are, respectively, $\sim 14$ and 24-27 times the horizontal grid spacing in d05, which lends further confidence that the resolution of CTLHR

\footnotetext{
${ }^{3}$ The wavelength of the most unstable mode would be less than this. For example, some studies (e.g., Miles and Howard 1964; Fritts and Rastogi 1985) have used 15 times the depth of the vertical shear layer, which would be approximately $10 \mathrm{~km}$ in the current case.
} 

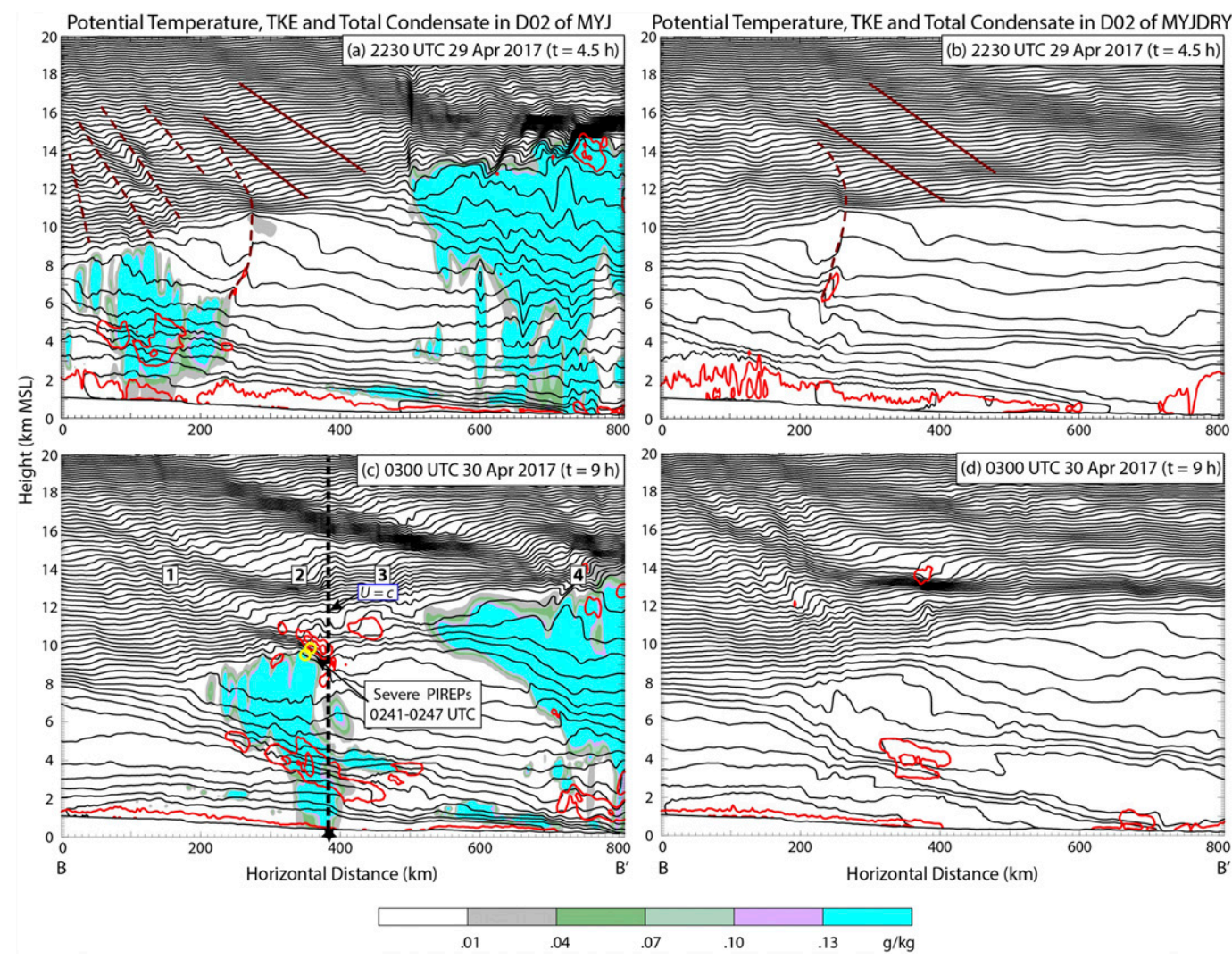

FIG. 11. Vertical cross sections of potential temperature (black contours, with 3-K contour intervals), turbulence kinetic energy (red contours, with $1 \mathrm{~m}^{2} \mathrm{~s}^{-2}$ contour intervals), and total cloud and hydrometeor content (color shading) along transect BB' of Fig. 12 (described below) for d02 of CTL at (a) 2230 UTC 29 Apr and (c) 0300 UTC 30 Apr 2017, and for d02 of DRY at (b) 2230 UTC 29 Apr and (d) 0300 UTC 30 Apr 2017. The thick brown lines in (a) and (b) indicate the phase lines of mesoscale waves discussed in the text, and the dashed brown lines indicate phase lines of shorter wavelengths locally excited by convection or tropospheric waves associated with the midtropospheric front. The annotated numbers in (c) indicate the horizontal position of the stratospheric waves at $150 \mathrm{hPa}$ shown in Fig. 10b. The open yellow circles in (c) indicate the locations of severe turbulence PIREPs (Fig. 3a) from 19 and 13 min earlier, which are projected onto the vertical cross section. The position within the cross section of the critical level $(U=c)$ at $11.9 \mathrm{~km}$ MSL from the Fig. 12a vertical profile at 0200 UTC is shown along the thick dashed line.

permits $\mathrm{KH}$ instability. However, at these altitudes the vertical grid spacing is $240 \mathrm{~m}$, which suggests that the depth of the low $\mathrm{Ri}$ layer could be only marginally resolved. It is unclear what effect this has on the characteristics of the simulated billows and should be a topic of continuing research.

Coinciding with the overturning isentropes in both cross sections are short horizontal- wavelength internal gravity waves, which are evidenced by the $1 / 4$ wavelength phase shifts between the potential temperature and vertical velocity perturbations in layers directly above and beneath the overturning isentropes (Figs. 16a,b). However, there are large differences in the vertical structure of the gravity waves occurring within these different vertical cross sections.

Reasons for the differences in vertical structure (Figs. 16a,b) are understood by analyzing vertical profiles of the approximate two-dimensional Scorer parameter (e.g., Nappo 2002):

$$
l^{2}=\frac{N^{2}}{(U-c)^{2}}-\frac{d^{2} U / d z^{2}}{U-c},
$$

where vertical profiles of $l^{2}$ are horizontally averaged in the same manner as the average depth $\Delta z$ of the $\mathrm{Ri}<0.25$ layers are estimated for Eq. (1). Gravity waves can propagate vertically when $l^{2}>k^{2}$ where $k=2 \pi / \lambda$ is the horizontal wavenumber. Waves are no longer able to propagate vertically at altitudes where $l^{2}-k^{2} \approx 0$, and are evanescent (i.e., experience vertical decay of amplitude) when $l^{2}<k^{2}$. Waves can become "trapped" in vertical regions between two evanescent or reflective (e.g., the ground) layers.

The waves in the SE-NW cross section (Fig. 16a) have a horizontal phase speed of $c=20 \mathrm{~m} \mathrm{~s}^{-1}$ based on animations of potential temperature using the 2-min frequency of model output from CTLHR. Here, the UTLS jet layer from $\sim 10.6$ to $11.4 \mathrm{~km}$ MSL (Fig. 17a) supports a wave duct with $l^{2} \approx k^{2}$ at these two levels (Fig. 17b), consistent with the vertically trapped appearance (i.e., lack of vertical tilt) of the gravity waves beneath the overturning isentropes (Fig. 16a). Gravity waves are predicted to be evanescent in the layer between 13.3 and $13.9 \mathrm{~km} \mathrm{MSL}$ (Fig. 17b) and above that altitude $l^{2}$ is close to $k^{2}$, 


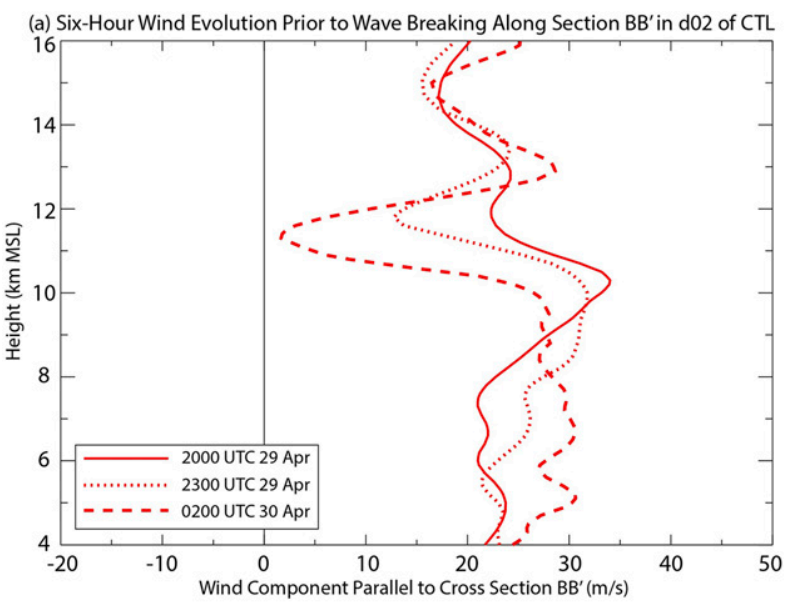

(b) CTL Reflectivity, 6-hr Wind Change along BB', and (CTL - DRY) Winds

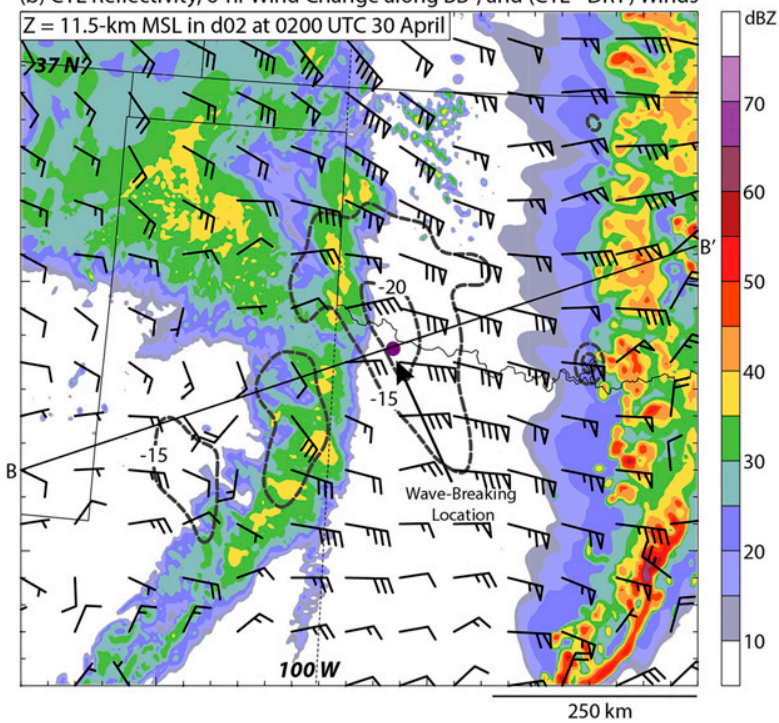

FIG. 12. (a) Evolution of the vertical profile of horizontal winds in the plane of transect $\mathrm{BB}^{\prime}$ of (b) at the location of the purple dot along $\mathrm{BB}^{\prime}$ in $\mathrm{d} 02$ of CTL. (b) The 6-h change in the component of the horizontal wind at $11.5 \mathrm{~km}$ MSL oriented along $\mathrm{BB}^{\prime}$ (dashed contours, with -15 , and $-20 \mathrm{~m} \mathrm{~s}^{-1}$ values), and maximum reflectivity in a vertical column at 0200 UTC 30 Apr 2017 for domain d02 of simulation CTL, and the $11.5 \mathrm{~km}$ MSL d02 (CTL - DRY) difference field of horizontal winds (barbed symbols plotted as in Figs. 2a,c) at 0200 UTC 30 Apr 2017.

which together are consistent with the decay of wave amplitude with height in this layer above the overturning isentropes and no vertical propagation farther aloft (Fig. 17a). It is also worth noting that there are two critical layers for these waves. The uppermost layer corresponds to the overturning region, consistent with stationary $\mathrm{KH}$ billows relative to the mean flow at that altitude. The second, at about $z=9.2 \mathrm{~km} \mathrm{MSL}$, is below the $\sim 1.5 \mathrm{~km}$ deep evanescent layer and the wave amplitude of any downward extending waves has already decayed to almost zero by this altitude.

The situation is different in vertical cross section SW-NE, wherein the isentropes overturn (Fig. 16b) in the layer of $\mathrm{Ri}<0.25$
Conditions in d02 at 1400 UTC 30 April $2017(t=22 \mathrm{~h})$
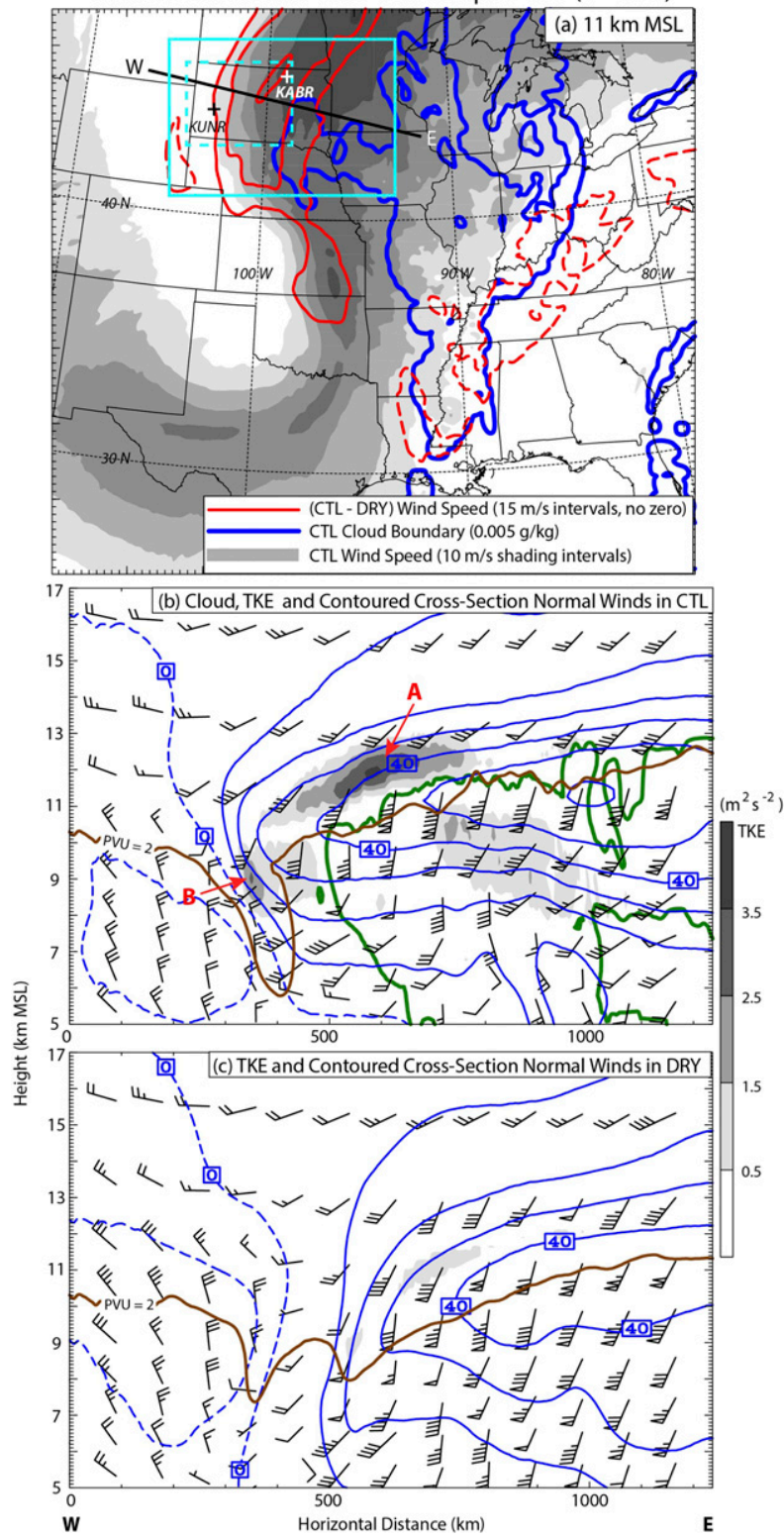

FIG. 13. (a) Composite map of $11-\mathrm{km}(\sim 36 \mathrm{kft})$ horizontal winds and cloud boundary from domain $\mathrm{d} 02$ of CTL and differences in wind speed from DRY (red contours) at 1400 UTC 30 Apr 2017. Transect WE locates the concurrent vertical cross sections of TKE (gray shading), horizontal winds, aggregate cloud water, cloud ice, and snow mixing ratio (single green contour $\geq 0.1 \mathrm{~g} \mathrm{~kg}^{-1}$ ), and approximate tropopause height [brown contour of 2 potential vorticity units (PVU); 1 PVU $=10^{-6} \mathrm{~K} \mathrm{~kg}^{-1} \mathrm{~m}^{2} \mathrm{~s}^{-1}$ ] for (b) CTL and (c) DRY. The dash-outlined interior cyan box in (a) locates domain d05 for the higher-resolution simulation CTLHR that is subsequently discussed.

located underneath the jet (Fig. 17c). In this cross section, the approximate horizontal wavelength of the associated gravity waves is greater $(\lambda \approx 9-10 \mathrm{~km})$ and the amplitude of the waves is less regular than in cross section SE-NW (cf. Figs. 16a,b). 
MREF, 8 and 10-km MSL Horizontal Winds, and 8-10-km MSL Vertical Shear Magnitude $>15 \mathrm{~m} \mathrm{~s}^{-1} \mathrm{~km}^{-1}$ in d02 of CTL

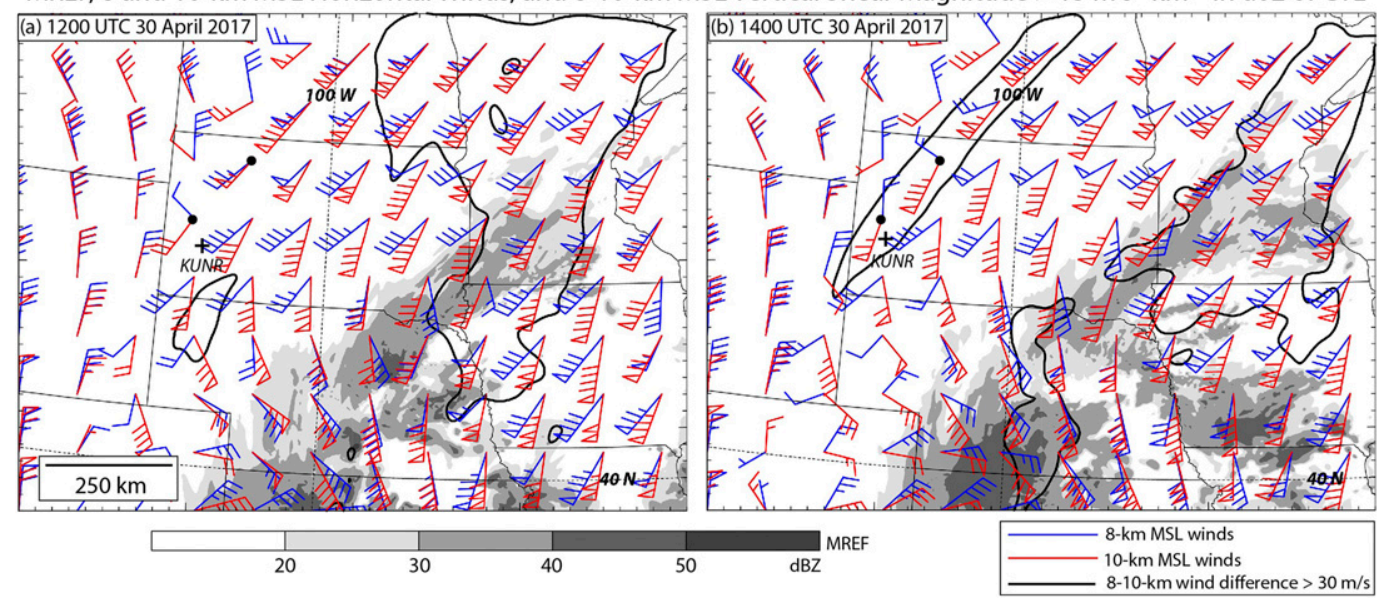

FIG. 14. Maximum reflectivity in the vertical column (gray shading), horizontal winds at $8 \mathrm{~km}$ MSL (blue barbed symbols with plotting convention as in Figs. 2a,c) and $10 \mathrm{~km} \mathrm{MSL} \mathrm{(red} \mathrm{barbed} \mathrm{symbols} \mathrm{with} \mathrm{plotting} \mathrm{convention} \mathrm{as}$ in Fig. 2a,c), and locations of vertical shear at $9 \mathrm{~km}$ MSL exceeding $15 \mathrm{~m} \mathrm{~s}^{-1} \mathrm{~km}^{-1}$ (single black contour) for a portion of domain d02 for CTL at (a) 1200 and (b) 1400 UTC 30 Apr 2017.

The undulations in the isentropes labeled 1 and 2 (Fig. 16b) were tracked with the 2-min model output during a 20-min period prior to which they overturned, and revealed an average horizontal phase speed of $c=18 \mathrm{~m} \mathrm{~s}^{-1}$ during this period. Substituting this estimated horizontal phase speed into (2) produces an average vertical profile of the Scorer parameter (Fig. 17d) that permits vertical wave propagation $\left(l^{2}>k^{2}\right)$ between a critical level located at $\sim 8.8 \mathrm{~km}$ MSL within the vertical shear layer beneath the jet where $\mathrm{Ri}<0.25$, and a second critical level located at $\sim 11.4 \mathrm{~km}$ MSL in the reverse shear above the jet (Fig. 17c).

This vertical structure is consistent with stationary (relative to the local mean flow) $\mathrm{KH}$ billows being generated in the $\mathrm{Ri}<$ 0.25 layer, which approximately coincides with the lower critical layer. These billows also generate gravity waves that are able to propagate vertically until they reach the uppermost critical layer, where they are dissipated (Fig. 16b). The dissipation of these upward propagating gravity waves provides a second possible source of turbulence in addition to that related to the overturning isentropes occurring in the vertical shear layer beneath the jet. Below the overturning billows the waves become evanescent at about $7.2 \mathrm{~km}$ MSL (Fig. 17d), consistent with the vertical decay patterns of downward propagating waves (Fig. 16b).

Gravity waves occurring approximately in phase with overturning isentropes that resemble $\mathrm{KH}$ billows have been observed in previous simulations. For instance, Trier et al. (2012) simulated similar layers of internal gravity waves located directly beneath and above KH-like overturning (their Fig. 14) in the entrance region of synoptic jet streak, and Zovko-Rajak and Lane (2014) found a similar horizontal juxtaposition of KH instability and short-wavelength internal gravity waves in their idealized simulations of turbulence in the UTLS outflows of mesoscale convective systems. Zovko-Rajak and Lane (2014) argued that the gravity waves were most likely initiated by the $\mathrm{KH}$ instability, but noted that because of the similar elevations of critical levels and layers of small $\mathrm{Ri}$ supporting $\mathrm{KH}$ instability, gravity wave breakdown near critical levels could not be entirely dismissed as the cause of the turbulence.

In the current case, potential temperature perturbations near the center of the SE-NW vertical cross section (Fig. 16a, dashed inset) originate in a layer of shearing instability $(\mathrm{Ri}<0.25)$ having lower static stability than surrounding layers (Fig. 18a). This unstable layer coincides with reverse shear above the convectively enhanced UTLS outflow (Fig. 18a), which constitutes the majority of the overall vertical shear within the unstable layer (cf. Fig. 17a).

As the perturbations amplify within the unstable layer, gravity waves are excited in surrounding layers with greater stratification (Figs. 18b,c). Consistent with the vertical structure of the Scorer parameter (Fig. 17b), these gravity waves are evanescent, and they remain in phase with the amplifying potential temperature perturbations within the $\mathrm{Ri}<0.25$ layer, where the isentropes begin overturning after 1216 UTC (Figs. 18d-f). This sequence of events points toward $\mathrm{KH}$ instability as the process that initiates the simulated wave breaking and turbulence, as suggested by Zovko-Rajak and Lane (2014). The behavior of the internal gravity waves both above and below the regions of $\mathrm{KH}$ instability are consistent with this conclusion.

Similar evolutions were found in additional vertical cross sections taken through other wavelike vertical velocity bands in Fig. 15a (not shown). Most notably, the potential temperature perturbations always originated within $\mathrm{Ri}<0.25$ layers possessing strong vertical shear located above the core of convectively enhanced UTLS outflow. Unlike in Fig. 18a, not all of these $\mathrm{Ri}<0.25$ layers possessed small static stability. However, the unstable layers that initially possessed small static stability, as in Fig. 18, often experienced the most rapid and widespread overturning.

The most common altitudes of observed turbulence (Fig. 8b) occurred from 10.7 to $12.5 \mathrm{~km}$ MSL (from $\sim 250$ to $175 \mathrm{hPa}$ ). 


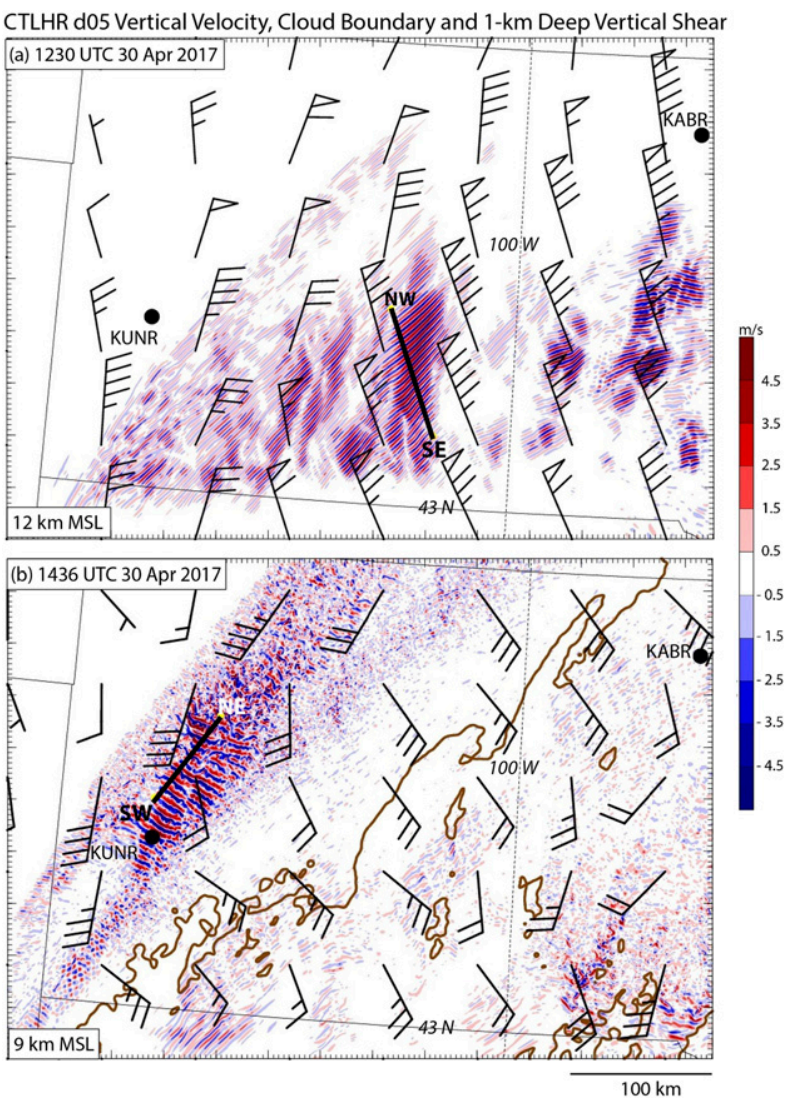

FIG. 15. Vertical velocity (color shading), cloud boundary (single brown $0.005 \mathrm{~g} \mathrm{~kg}^{-1}$ contour), and 1-km horizontal wind difference (bulk vertical shear; barbed symbols plotted as in Figs. 2a,c) in domain d05 of CTLHR located at (a) $12 \mathrm{~km}$ MSL at 1230 UTC 30 Apr 2017 and (b) $9 \mathrm{~km}$ MSL at 1420 UTC 30 Apr 2017. The transect SE-NW in (a) indicates the horizontal location of vertical cross sections displayed in Figs. 16a and 17a, below. The transect SW-NE in (b) indicates the horizontal location of vertical cross sections displayed in Figs. $16 \mathrm{~b}$ and $17 \mathrm{c}$, below. The annotations KABR and KUNR locate NWS soundings for which wind speeds are plotted in Figs. 5b and 5d, respectively.

Figure 19 shows $3 \mathrm{~h}$ of observed turbulence reports from within this layer superposed on the CTLHR 1420 UTC 30 April horizontal winds and vertical velocities at 10.75 MSL. The simulated vertical velocities comprise intermittent wavelike banded features interspersed over a widespread region outside of cloud. The wider bands with larger horizontal wavelengths at the western edge of the observed turbulence correspond to the vertically propagating gravity waves (dashed phase lines in Fig. 16b) below the level at which they break and induce turbulence. The bands located in the stronger UTLS outflow farther east (in the region enclosed by the dashed cone of Fig. 19) constitute packets of trapped gravity waves of shorter horizontal wavelength, which are akin to those occurring $\sim 2 \mathrm{~h}$ earlier (Figs. 16a and 18e,f) beneath overturning waves at altitudes with $\mathrm{KH}$ instability.

It is noteworthy that the region of model-parameterized $\mathrm{TKE}$ at $200 \mathrm{hPa}$ in $\mathrm{d} 04$ of the lower maximum resolution $(\Delta x=$

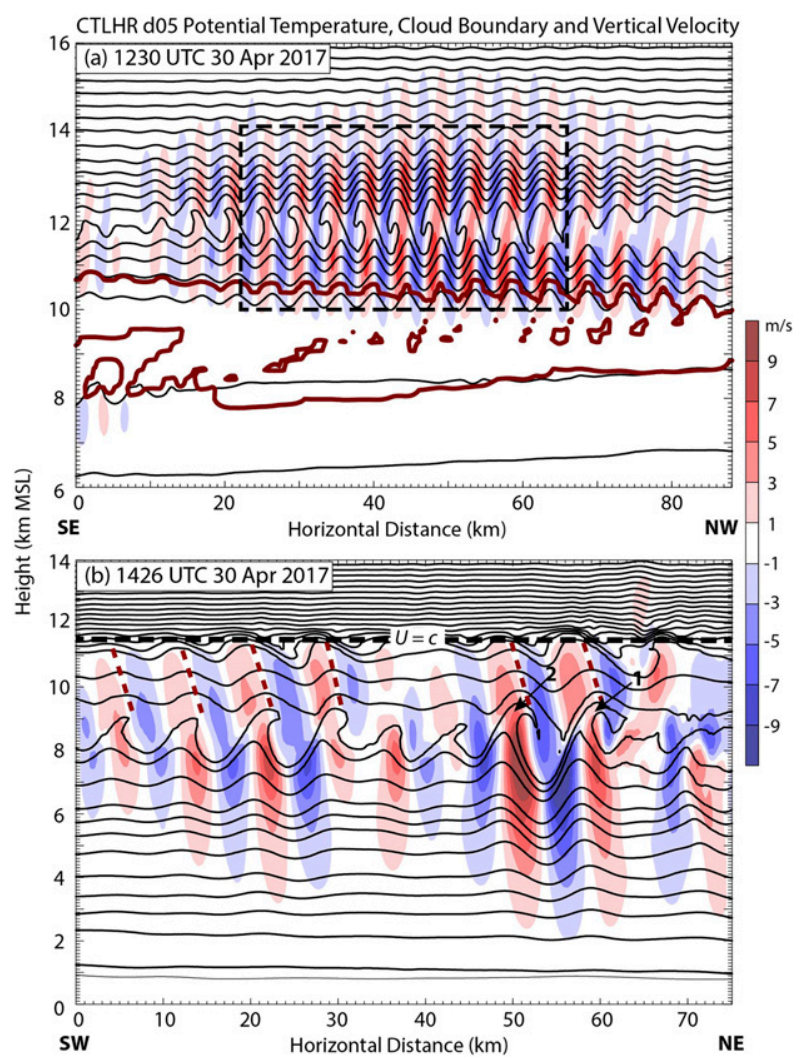

FIG. 16. Vertical cross section along transects of vertical velocity (color shading), potential temperature (black contours, with 3-K contour intervals), and cloud boundary (brown contour of $0.005 \mathrm{~g} \mathrm{~kg}^{-1}$ ) along transects (a) SE-NW of Fig. 15a at 1230 UTC 30 Apr 2017 and (b) SW-NE of Fig. 15b at 1426 UTC 30 Apr 2017 for d05 of CTLHR. The dash-outlined rectangle in (a) indicates the display domain for Fig. 18. The thick dashed horizontal line in (b) indicates the altitude of a critical level at which gravity waves (brown dashed phase lines) are unable to vertically propagate, also shown later in an analysis of the Scorer parameter in Fig. 17d. The annotations 1 and 2 indicate individual waves that are tracked to determine a mean horizontal phase speed used in the Scorer parameter calculations of Fig. 17d.

$1.1 \mathrm{~km}$ ) simulation CTL (Fig. 8b) coincides well with this more eastward region containing the banded vertical velocity features and the numerous reports of moderate and severe turbulence in Fig. 19. Similarly, there is large model-parameterized TKE in d04 of CTL at $300 \mathrm{hPa}$ (Fig. 8a) in the general region of the lower altitude 9-km MSL $(\sim 300 \mathrm{hPa})$ vertical velocity bands north of KUNR (cf. Fig. 15b).

\section{Summary and discussion}

The environment and mechanisms of widespread aviation turbulence within a strong springtime baroclinic wave cyclone have been examined using observations and nested grid simulations, which identify the synoptic and mesoscale features that are conducive to turbulence. There were over 1100 reports of moderate or greater turbulence from in situ EDR data and PIREPs in the upper troposphere/lower 


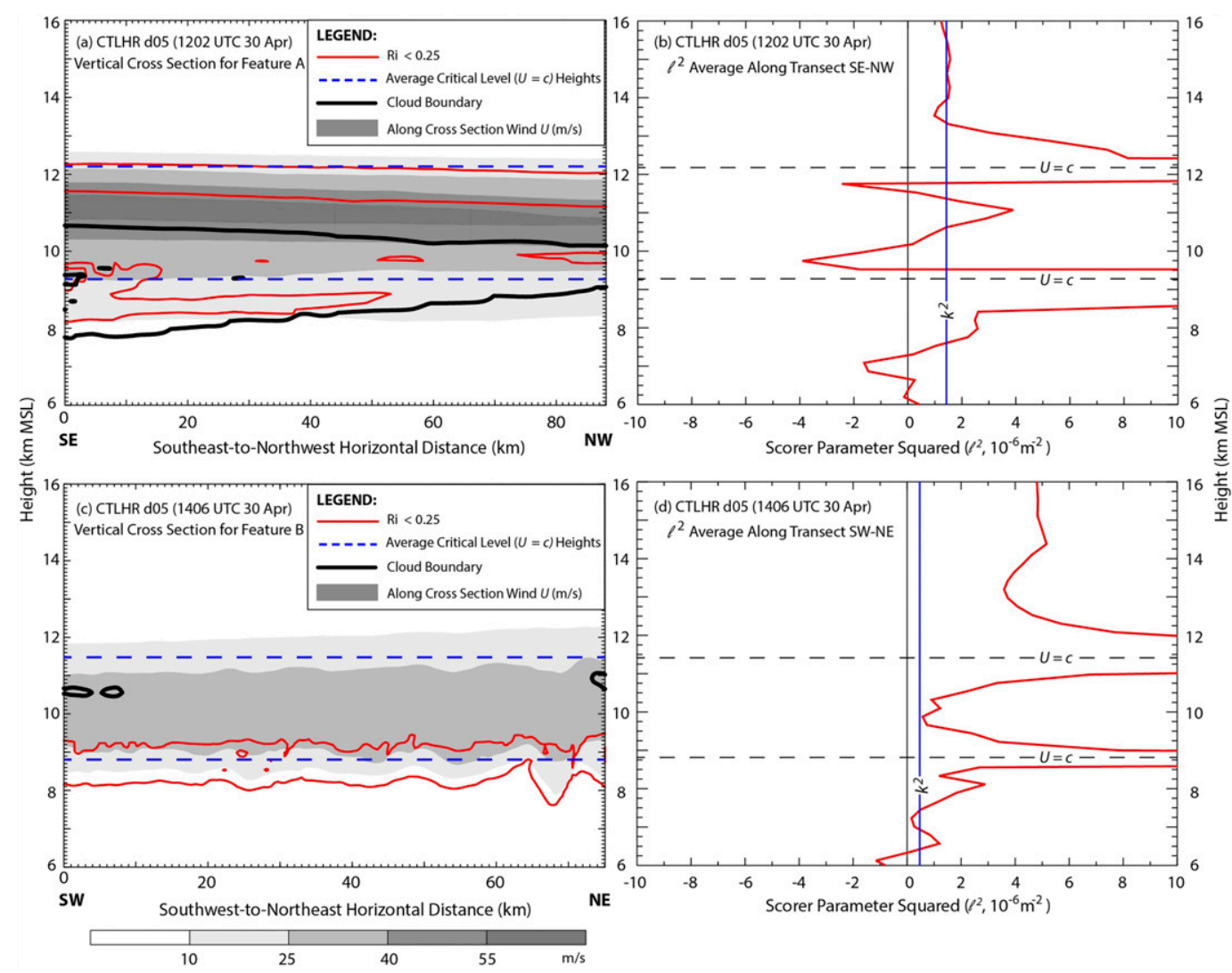

FIG. 17. (a),(c) Vertical cross sections of the environmental features indicated in the legend for the corresponding vertical cross sections of Figs. 16a and 16b, respectively, prior to widespread wave breaking. (b),(d) Vertical profiles of the Scorer parameter corresponding to (a),(b), respectively. In (b)and (d), $k^{2}$ refers to the square of the horizontal wavenumber discerned from Figs. 16a and 16b, respectively.

stratosphere east of the Rocky Mountains from 0000 to 1800 UTC 30 April 2017, including over 100 reports of severe turbulence.

These springtime baroclinic wave cyclones are common in the lee of the Rockies and are a frequent source of disruptive aviation turbulence. Regions within the cyclone most supportive of severe turbulence for the current case are summarized relative to synoptic features in Fig. 20. This schematic shares some similarities with diagrams of preferred locations of jet stream turbulence in midlatitude cyclones presented in previous works (e.g., Hopkins 1977; Ellrod and Knapp 1992; Ellrod et al. 2015; Knox et al. 2016). However, the current study emphasizes that the severe turbulence that occurs in each of three shaded regions in Fig. 20 is strongly influenced by organized deep convection within the cyclone. Among these three shaded regions, the two we concentrated on (regions 1 and 2) do not occur directly within strong convection.

The persistence, spatial extent, and simulated turbulence mechanisms were distinctly different in these two regions. In both regions, the majority of the reported turbulence occurred outside of cloud. Despite the majority of the turbulence being in clear air, comparisons with a dry simulation in which cloud microphysical processes were withheld, established that anticyclonic UTLS outflow emanating from deep convection elsewhere in the midlatitude cyclone played crucial roles in enhancing the vertical wind shear. This underscores the importance of moist convection in altering the environment in the clear air, making it more susceptible to turbulence.

In region 1, which is located along a midtropospheric front in western Texas, the turbulence was relatively isolated and transient. Model-parameterized TKE in this region of the full-physics simulation was associated with breaking mesoscale lower-stratospheric gravity waves. These mesoscale waves had horizontal wavelengths of $\sim 100 \mathrm{~km}$, and occurred in a jet exit region near the base of the UTLS synoptic trough (Fig. 20).

Mesoscale wave breaking also occurred in this horizontal location in a dry simulation, but in that simulation the wave breaking was restricted to altitudes several kilometers above that of the observed turbulence and the corresponding wavebreaking in the full-physics simulation. In the full-physics simulation, UTLS outflow from deeper and more intense convection located along the surface cold front modified the vertical profile of horizontal winds along the direction of wave propagation and influenced the altitude of a critical level, underneath which simulated wave breaking occurred. The relatively long wavelengths of these gravity waves 
CTLHR Potential Temperature, $\mathrm{Ri}=0.25$ (red lines), and (CTLHR - DRYHR) Winds Along Cross Section
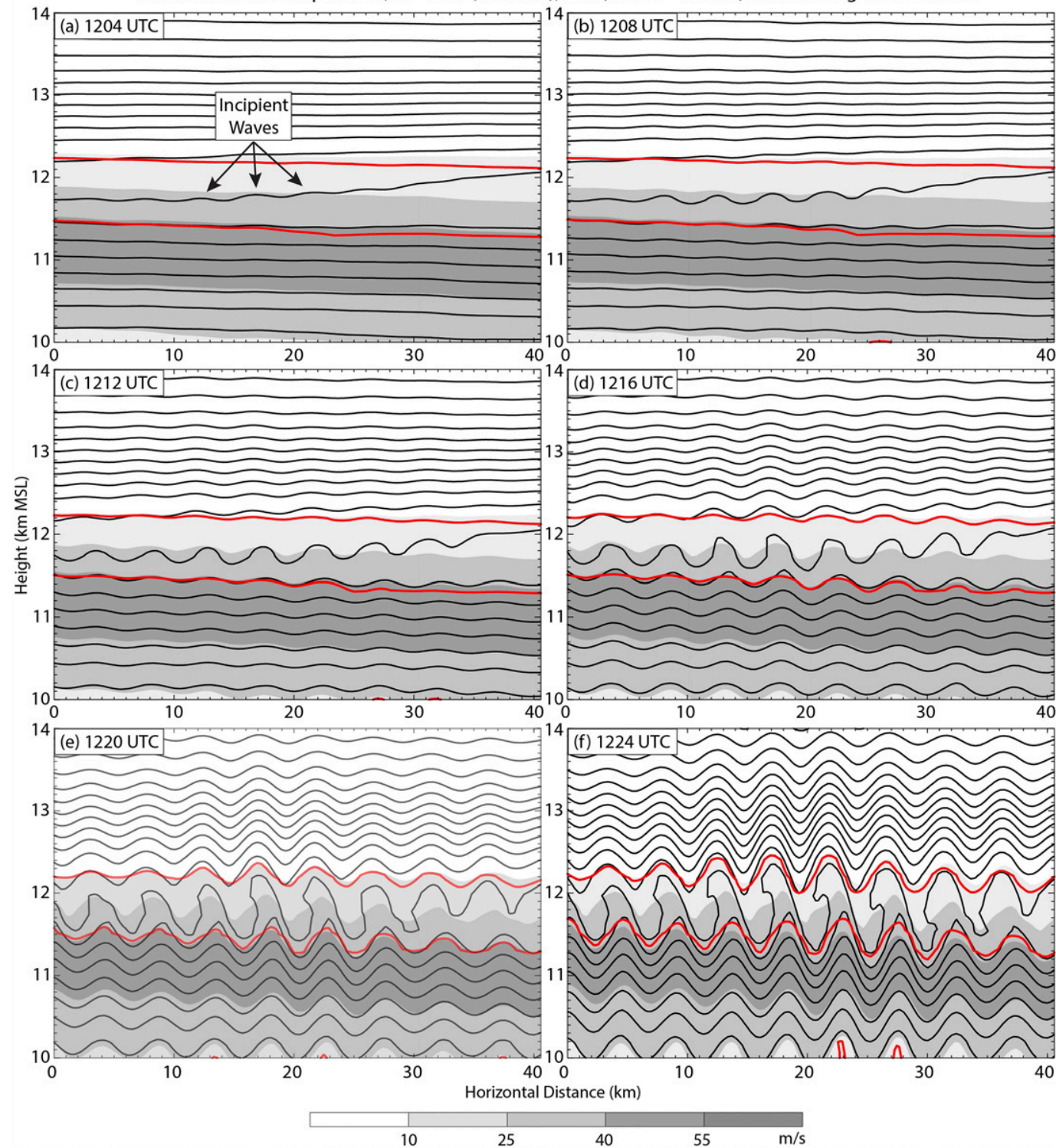

FIG. 18. Evolution of CTLHR potential temperature (black contours, with 3-K intervals), gradient Richardson number $=0.25$ (red contours), and (CTLHR - DRYHR) horizontal winds (shading) oriented along SE-NW (Fig. 15a) for the dash-outlined inset of Fig. 16a from (a) 1204-(f) 1224 UTC 30 Apr 2017.

combined with UTLS outflow from distant convection to locally establish a critical level near or slightly above commercial aviation cruising altitudes may help explain the relatively isolated nature of the observed turbulence in this region.

In contrast, both the observed turbulence and modelparameterized TKE occurred was more persistent and widespread over region 2 (Fig. 20), which was located over the northern plains. For the eastern part of the region (marked $2 \mathrm{a}$ in Fig. 20) the turbulence altitude was centered near $12 \mathrm{~km}$ MSL $(200 \mathrm{hPa})$, which was $\sim 1 \mathrm{~km}$ above the northwestern edge of the extensive cloud shield whose top coincided with the altitude of the UTLS southerly jet that occurred ahead of the synoptic trough. The wind speeds in the UTLS jet were enhanced by $30-45 \mathrm{~m} \mathrm{~s}^{-1}$ due to anticyclonic outflow from organized deep convection occurring within the cyclone warm sector to the southeast (Fig. 20). The waves in this region had much smaller horizontal wavelengths of $\sim 5 \mathrm{~km}$ than those associated with the more transient turbulence in region 1 , and were consistent with $\mathrm{KH}$ instability since they both initiated and overturned at altitudes where $\mathrm{Ri}<0.25$ in the vertical shear layer located above the UTLS jet.

In region $2 \mathrm{~b}$ (Fig. 20), a second shorter-lived area of enhanced model-parameterized TKE occurred west of the synoptic cloud shield within a tropopause fold located 


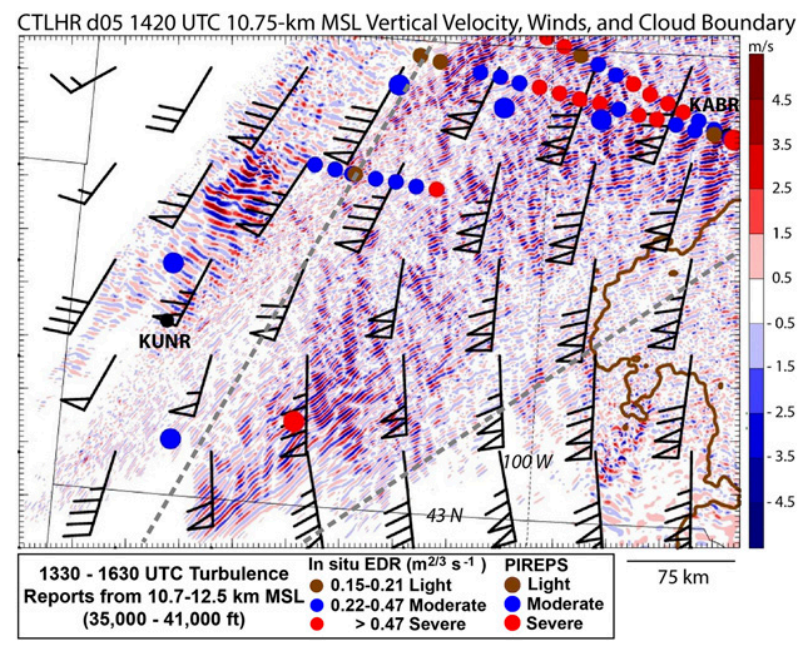

FIG. 19. Vertical velocity (color shading), horizontal winds (barbed symbols as in Figs. 2a,c), and cloud condensate boundary (brown contour of $q_{c}=0.005 \mathrm{~g} \mathrm{~kg}^{-1}$ ) at 1420 UTC $30 \mathrm{Apr} 2017$ for d05 of CTLHR at $z=10.75 \mathrm{~km}$ MSL. Observed turbulence reports surrounding this altitude are superimposed as indicated in the legend. For comparison purposes (see text), the dashed gray wedge-shaped region corresponds to the region of significant modelparameterized turbulence kinetic energy in the lower-resolution domain d04 of CTL (cf. Fig. 8d) and TKE feature A of d02 of CTL (cf. Fig. 13b).

closer the UTLS trough axis. This location contained simulated waves with horizontal wavelengths of $\sim 10 \mathrm{~km}$, and these waves overturned within a layer with $\mathrm{Ri}<0.25$ at an altitude about $3 \mathrm{~km}$ lower ( $\sim 9 \mathrm{~km}$ MSL) in weaker vertical shear beneath the UTLS jet. These overturning waves were overlaid by vertically propagating internal gravity waves, which themselves overturned near a critical level located in the reverse shear above the UTLS jet. The multiple layers of simulated wave overturning at this horizontal location is consistent with observed reports of moderate-or-greater turbulence through several $\mathrm{km}$ along and immediately east of the UTLS synoptic trough axis.

In summary, our highest-resolution nested NWP simulation with 370-m minimum horizontal grid spacing indicates smallscale wave breaking as the likely mechanism influencing the onset of widespread observed out-of-cloud turbulence in two distinct regions in region 2 (Fig. 20). However, this simulation is still inadequate for the purpose of reliably capturing details of the wave to turbulence breakdown process in both of these turbulence regions. Examination of this process would require direct numerical simulation studies (e.g., Fritts et al. 2009a,b). Another limitation of the current study and for model-based UTLS turbulence studies in general, is the lack of thermodynamic and wind information at the horizontal scales necessary to verify the simulated turbulence onset from wave breaking.

However, the broad agreement of model-parameterized TKE in the control simulation with observed in situ data and PIREPs of severe turbulence, together with similar approximate collocation of explicitly simulated wave-breaking in our highest-resolution simulation, is an encouraging finding. This
Turbulence Hazard Regions in a United States Lee Cyclone

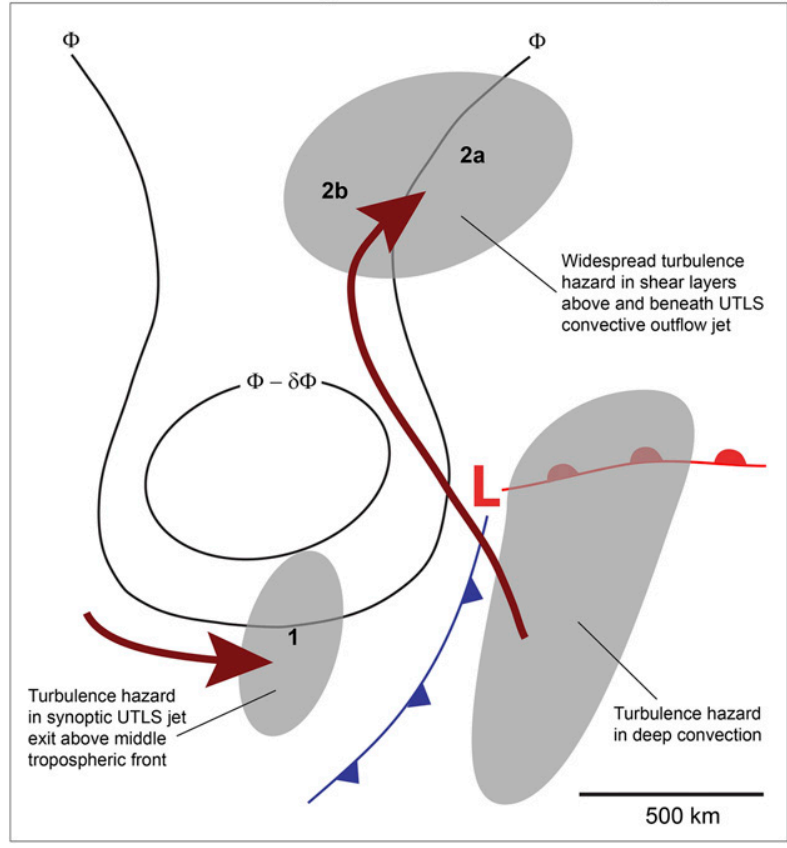

FIG. 20. Schematic diagram illustrating the locations of turbulence hazard regions (shaded) occurring near the jet-stream level and their spatial relationships to the illustrated large-scale meteorological features observed and simulated in the $30 \mathrm{Apr}$ 2017 lee cyclone. The red L and the blue and red lines with symbols indicate the positions of the surface cyclone and the cold and warm fronts, respectively. The thin black lines depict UTLS geopotential height contours. The short and long brown arrows depict a synoptic UTLS jet streak near the base of the geopotential trough, and the maximum jet stream winds on the east side of the geopotential trough (which are enhanced by UTLS convective outflow), respectively. The numerical annotations indicate approximate locations referred to in the summary text.

suggests that the current highest-resolution operational models $(\Delta x=1-3 \mathrm{~km})$ are capable of simulating these regions of TKE and related turbulence hazards provided that deep convection and its associated UTLS outflow is accurately represented in these models.

However, the accurate prediction of deep convection itself is a challenging problem, and depends on many factors including the appropriateness of subgrid physical parameterizations used in operational models. In particular, the model PBL scheme influences attributes of UTLS outflows (including vertical shear, and static stability), which can in turn influence the model-parameterized TKE, and resolved flow quantities that may be predictors of turbulence (e.g., Sharman and Pearson 2017; Williams 2017). This can happen both indirectly through the PBL scheme's influence on deep convection, or more directly by the vertical mixing controlled by the PBL scheme, since these schemes redistribute momentum and scalar quantities throughout the entire model depth in most NWP models. These effects related to the PBL scheme are explored using the current case as an example in a companion paper (Muñoz-Esparza et al. 2020). 
Acknowledgments. The authors acknowledge Wiebke Deierling (NCAR) and Andreas Dörnbrack (German Aerospace Center Institute of Atmospheric Physics) for beneficial discussions about this research and three anonymous reviewers for their comments, which resulted in improvements to the paper. This research is in response in part to requirements and funding by the Federal Aviation Administration (FAA). The views expressed are those of the authors and do not necessarily represent the official policy of the FAA. Author T. P. Lane's involvement in this work is supported by the Australian Research Council's Discovery Program (DP200102516). The National Center for Atmospheric Research is sponsored by the National Science Foundation.

Data availability statement. All simulations reported in this study will be made available from the corresponding author upon request.

\section{REFERENCES}

Barber, K. A., G. L. Mullendore, and M. J. Alexander, 2018: Out-of-cloud convective turbulence: Estimation method and impacts of model resolution. J. Appl. Meteor. Climatol., 57, 121-136, https://doi.org/10.1175/JAMC-D-17-0174.1.

Browning, K. A., 1971: Structure of the atmosphere in the vicinity of large-amplitude Kelvin-Helmholtz billows. Quart. J. Roy. Meteor. Soc., 97, 283-299, https://doi.org/10.1002/ qj.49709741304.

Danielsen, E. F., 1968: Stratospheric-tropospheric exchange based on radioactivity, ozone, and potential vorticity. J. Atmos. Sci., 25, 502-518, https://doi.org/10.1175/1520-0469(1968)025<0502: STEBOR $>2.0 . \mathrm{CO} ; 2$.

Dörnbrack, A., T. Gerz, and U. Schumann, 1995: Turbulent breaking of overturning gravity waves below a critical level. Appl. Sci. Res., 54, 163-176, https://doi.org/10.1007/BF00849114.

Ek, M. B., K. E. Mitchell, Y. Lin, E. Rogers, P. Grummann, V. Koren, G. Gayno, and J. D. Tarpley, 2003: Implementation of Noah land surface model advances in the National Centers for Environmental Prediction operational mesoscale Eta model.J. Geophys. Res., 108, 8851, https://doi.org/ 10.1029/2002JD003296.

Ellrod, G. P., and D. L. Knapp, 1992: An objective clear-air turbulence forecasting technique: Verification and operational use. Wea. Forecasting, 7, 150-165, https://doi.org/10.1175/ 1520-0434(1992)007<0150:AOCATF > 2.0.CO;2.

— , J. A. Knox, P. F. Lester, and L. J. Ehernberger, 2015: Clear air turbulence. Encyclopedia of Atmospheric Science, 2nd ed. G. R. North, J. Pyle, and F. Zhang, Eds., Academic Press, 177-186.

Emanuel, K. A., 1994: Atmospheric Convection. Oxford University Press, $580 \mathrm{pp}$.

Fovell, R. G., D. Durran, and J. R. Holton, 1992: Numerical simulations of convectively-generated stratospheric gravity waves. J. Atmos. Sci., 49, 1427-1442, https://doi.org/10.1175/15200469(1992)049<1427:NSOCGS > 2.0.CO;2.

Fritts, D. C., and P. K. Rastogi, 1985: Convective and dynamic instabilities due to gravity wave motions in the lower and middle atmosphere: Theory and observations. Radio Sci., 20, 1247-1277, https://doi.org/10.1029/RS020i006p01247.

_- , and M. J. Alexander, 2003: Gravity wave dynamics and effects in the middle atmosphere. Rev. Geophys., 41, 1003, https://doi.org/10.1029/2001RG000106.
— L. Wang, J. Werne, T. Lund, and K. Wan, 2009a: Gravity wave instability dynamics at high Reynolds numbers. Part I: Wave field evolution at large amplitudes and high frequencies. J. Atmos. Sci., 66, 1126-1148, https://doi.org/10.1175/2008JAS2726.1.

,,,,---- and,$- 2009 \mathrm{~b}$ : Gravity wave instability dynamics at high Reynolds numbers. Part II: Turbulence evolution, structure and anisotropy. J. Atmos. Sci., 66, 1149-1171, https://doi.org/10.1175/2008JAS2727.1.

Geerts, B., and Q. Miao, 2010: Vertically pointing airborne Doppler radar observations of Kelvin-Helmholtz billows. Mon. Wea. Rev., 138, 982-986, https://doi.org/10.1175/ 2009MWR3212.1.

Grasmick, C., and B. Geerts, 2020: Detailed dual-Doppler structure of Kelvin-Helmholtz waves from an airborne profiling radar over complex terrain. Part I: Dynamic structure. J. Atmos. Sci., 77, 1761-1782, https://doi.org/10.1175/ JAS-D-19-0108.1.

Hopkins, R. H., 1977: Forecasting techniques of clear-air turbulence including that associated with mountain waves. WMO Tech. Note 155, $31 \mathrm{pp}$.

Iacono, M. J., J. S. Delamere, E. J. Mlawer, M. W. Shephard, S. A. Clough, and W. D. Collins, 2008: Radiative forcing by longlived greenhouse gases: Calculations with the AER radiative transfer models. J. Geophys. Res., 113, D13103, https://doi.org/ 10.1029/2008JD009944.

Janjić, Z. I., 1994: The step-mountain Eta coordinate model: Further developments of the convection, viscous sublayer, and turbulence closure schemes. Mon. Wea. Rev., 122, 927-945, https://doi.org/10.1175/1520-0493(1994)122<0927:TSMECM> 2.0.CO;2.

- 2001: Nonsingular implementation of the Mellor-Yamada level 2.5 scheme in the NCEP Meso Model. NCEP Office Note 437, $61 \mathrm{pp}$.

Kennedy, P. J., and M. A. Shapiro, 1980: Further encounters with clear-air turbulence in research aircraft. J. Atmos. Sci., 37, 986-993, https://doi.org/10.1175/1520-0469(1980)037<0986: FEWCAT $>2.0$. CO;2.

Keyser, D., and M. A. Shapiro, 1986: A review of the structure and dynamics of upper-level frontal zones. Mon. Wea. Rev., 114, 452-499, https://doi.org/10.1175/1520-0493(1986)114<0452: AROTSA $>2.0 . \mathrm{CO} ; 2$.

Kim, J.-H., and H.-Y. Chun, 2010: A numerical study of clear-air turbulence (CAT) encounters over South Korea on 2 April 2007. J. Appl. Meteor. Climatol., 49, 2381-2403, https://doi.org/ 10.1175/2010JAMC2449.1.

- , and - 2012: A numerical investigation of convectively induced turbulence above deep convection. J. Appl. Meteor. Climatol., 51, 1180-1200, https://doi.org/10.1175/JAMC-D-110140.1.

,-- , R. D. Sharman, and S. B. Trier, 2014: The role of vertical shear on aviation turbulence within cirrus bands of a simulated western Pacific cyclone. Mon. Wea. Rev., 142, 2794-2813, https://doi.org/10.1175/MWR-D-14-00008.1.

Klemp, J. B., J. Dudhia, and A. D. Hassiotis, 2008: An upper gravitywave absorbing layer for NWP applications. Mon. Wea. Rev., 136, 3987-4004, https://doi.org/10.1175/2008MWR2596.1.

Klostermeyer, J., and R. Rüster, 1980: Radar observation and model computation of jet stream-generated Kelvin-Helmholtz instability. J. Geophys. Res., 85, 2841-2846, https://doi.org/ 10.1029/JC085iC05p02841.

Knox, J. A., A. W. Black, J. A. Rackley, E. N. Wilson, J. S. Grant, S. P. Phelps, D. S. Nevius, and C. B. Dunn, 2016: Automated turbulence forecasting strategies. Aviation Turbulence: Processes, 
Detection, Prediction, R. Sharman and T. Lane, Eds., Springer, 243-260.

Koch, S. E., and P. B. Dorian, 1988: A mesoscale gravity wave event observed during CCOPE. Part III: Wave environment and probable source mechanisms. Mon. Wea. Rev., 116, 2570-2592, https://doi.org/10.1175/1520-0493(1988) 116<2570:AMGWEO>2.0.CO;2.

— , and Coauthors, 2005: Turbulence and gravity waves within an upper-level front. J. Atmos. Sci., 62, 3885-3908, https:// doi.org/10.1175/JAS3574.1.

Lane, T. P., and J. C. Knievel, 2005: Some effects of model resolution on simulated gravity waves generated by deep, mesoscale convection. J. Atmos. Sci., 62, 3408-3419, https://doi.org/ 10.1175/JAS3513.1.

_- , and R. D. Sharman, 2008: Some influences of background flow conditions on the generation of turbulence due to gravity wave breaking above deep convection. J. Appl. Meteor. Climatol., 47, 2777-2796, https://doi.org/10.1175/ 2008JAMC1787.1.

$\longrightarrow$, and — 2014: Intensity of thunderstorm-generated turbulence as revealed by large-eddy simulation. Geophys. Res. Lett., 41, 2221-2227, https://doi.org/10.1002/2014GL059299.

,-- T. T. Clark, and H. M. Hsu, 2003: An investigation of turbulence generation mechanisms above deep convection. J. Atmos. Sci., 60, 1297-1321, https://doi.org/10.1175/15200469(2003)60<1297:AIOTGM>2.0.CO;2.

_ J. D. Doyle, R. Plougonven, M. A. Shapiro, and R. D. Sharman, 2004: Observations and numerical simulations of intertiagravity waves and shearing instabilities in the vicinity of a jet stream. J. Atmos. Sci., 61, 2692-2706, https://doi.org/10.1175/ JAS3305.1.

—, R. D. Sharman, S. B. Trier, R. G. Fovell, and J. K. Williams, 2012: Recent advances in the understanding of near-cloud turbulence. Bull. Amer. Meteor. Soc., 93, 499-515, https:// doi.org/10.1175/BAMS-D-11-00062.1.

Ludlam, F. H., 1967: Characteristics of billow clouds and their relation to clear-air turbulence. Quart. J. Roy. Meteor. Soc., 93, 419-435, https://doi.org/10.1002/qj.49709339803.

Mancuso, R. L., and R. M. Endlich, 1966: Clear air turbulence frequency as a function of wind shear and deformation. Mon. Wea. Rev., 94, 581-585, https://doi.org/10.1175/1520-0493(1966) 094<0581:CATFAA > 2.3.CO;2.

Miles, J., 1986: Richardson's criterion for the stability of stratified shear flow. Phys. Fluids, 29, 3470-3471, https://doi.org/ 10.1063/1.865812.

— Mech., 20, 331-336, https://doi.org/10.1017/S0022112064001252.

Mlawer, E. J., S. J. Taubman, P. D. Brown, M. J. Iacono, and S. A. Clough, 1997: Radiative transfer for inhomogeneous atmospheres: RRTM, a validated correlated- $k$ model for the longwave. J. Geophys. Res., 102, 16 663-16 682, https://doi.org/ 10.1029/97JD00237.

Muñoz-Esparza, D., R. D. Sharman, and S. B. Trier, 2020: On the consequences of PBL scheme diffusion on UTLS wave and turbulence representation in high-resolution NWP models. Mon. Wea. Rev., 148, 4247-4265, https://doi.org/10.1175/ MWR-D-20-0102.1.

Nappo, C. J., 2002: An Introduction to Atmospheric Gravity Waves. Academic Press, 276 pp.

Plougonven, R., and F. Zhang, 2016: Gravity waves generated by jets and fronts and their relevance for clear-air turbulence. Aviation Turbulence: Processes, Detection, Prediction, R. Sharman and T. Lane, Eds., Springer, 385-406.
Scorer, R. S., 1969: Billow mechanics. Radio Sci., 4, 1299-1308, https://doi.org/10.1029/RS004i012p01299.

Shapiro, M. A., 1978: Further evidence of the mesoscale turbulent structure of upper-level jet stream-frontal zone systems. Mon. Wea. Rev., 106, 1100-1111, https://doi.org/10.1175/15200493(1978)106<1100:FEOTMA > 2.0.CO;2.

, 1980: Turbulent mixing within tropopause folds as a mechanism for exchange of chemical constituents between the stratosphere and troposphere. J. Atmos. Sci., 37, 994-1004, https://doi.org/ 10.1175/1520-0469(1980)037<0994:TMWTFA > 2.0.CO;2.

Sharman, R., 2016: Nature of aviation turbulence. Aviation Turbulence: Processes, Detection, Prediction, R. Sharman and T. Lane, Eds., Springer, 3-30.

— , and J. Pearson, 2017: Prediction of energy dissipation rates for aviation turbulence. Part I: Forecasting non-convective turbulence. J. Appl. Meteor. Climatol., 56, 317-337, https:// doi.org/10.1175/JAMC-D-16-0205.1.

— convectively-induced turbulence (CIT): A review. Pure Appl. Geophys., 176, 1923-1958, https://doi.org/10.1007/s00024-0181849-2.

— L. B. Cornman, G. Meymaris, J. Pearson, and T. Farrar, 2014: Description and derived climatologies of automated in situ eddy-dissipation-rate reports of atmospheric turbulence. J. Appl. Meteor. Climatol., 53, 1416-1432, https://doi.org/10.1175/JAMCD-13-0329.1.

Skamarock, W. C., and J. B. Klemp, 2008: A time-split nonhydrostatic atmospheric model for weather research and forecasting applications. J. Comput. Phys., 227, 3465-3485, https://doi.org/ 10.1016/j.jcp.2007.01.037.

Smith, T. L., S. G. Benjamin, J. M. Brown, S. S. Weygandt, T. Smirnova, and B. E. Schwartz, 2008: Convection forecasts from the hourly updated, 3-km High Resolution Rapid Refresh (HRRR) model. 24th Conf. on Severe Local Storms, Savannah, GA, Amer. Meteor. Soc., 11.1, http://ams.confex.com/ams/ pdfpapers/142055.pdf.

Thompson, G., P. R. Field, R. M. Rasmussen, and W. D. Hall, 2008: Explicit forecasts of winter precipitation using an improved bulk microphysics scheme. Part II: Implementation of a new snow parameterization. Mon. Wea. Rev., 136, 5095-5115, https://doi.org/10.1175/2008MWR2387.1.

Tiedtke, M., 1989: A comprehensive mass flux scheme for cumulus parameterization in large-scale models. Mon. Wea. Rev., 117, 1779-1800, https://doi.org/10.1175/1520-0493(1989)117<1779: ACMFSF $>2.0 . \mathrm{CO} ; 2$.

Trier, S. B., and R. D. Sharman, 2016: Mechanisms influencing cirrus banding and aviation turbulence near a convectively enhanced upper-level jet stream. Mon. Wea. Rev., 144, 30033027, https://doi.org/10.1175/MWR-D-16-0094.1.

$\longrightarrow$, and - , 2018: Trapped gravity waves and their association with turbulence in a large thunderstorm anvil during PECAN. Mon. Wea. Rev., 146, 3031-3052, https://doi.org/10.1175/ MWR-D-18-0152.1.

- — , R. G. Fovell, and R. G. Frehlich, 2010: Numerical simulation of radial cloud bands within the upper-level outflow of an observed mesoscale convective system. J. Atmos. Sci., 67, 2990-2999, https://doi.org/10.1175/2010JAS3531.1.

— - _ and T. P. Lane, 2012: Influences of moist convection on a cold-season outbreak of clear-air turbulence (CAT). Mon. Wea. Rev., 140, 2477-2496, https://doi.org/10.1175/ MWR-D-11-00353.1.

Uccellini, L. W., and S. E. Koch, 1987: The synoptic setting and possible energy sources for mesoscale wave disturbances. 
Mon. Wea. Rev., 115, 721-729, https://doi.org/10.1175/15200493(1987)115<0721:TSSAPE $>2.0$.CO;2.

Williams, P. D., 2017: Increased light, moderate, and severe clear-air turbulence in response to climate change. $A d v$. Atmos. Sci., 34, 576-586, https://doi.org/10.1007/s00376017-6268-2.

Wroblewski, D. E., O. R. Coté, J. M. Hacker, and R. J. Dobosy, 2007: Cliff-Ramp patterns and Kelvin-Helmholtz billows in stably stratified shear flow in the upper troposphere: Analysis of aircraft measurements. J. Atmos. Sci., 64, 25212539, https://doi.org/10.1175/JAS3956.1.
Zhang, F., 2004: Generation of mesoscale gravity waves in uppertropospheric jet-front systems. J. Atmos. Sci., 61, 440-457, https://doi.org/10.1175/1520-0469(2004)061<0440:GOMGWI> 2.0.CO;2.

Zovko-Rajak, D., and T. P. Lane, 2014: The generation of nearcloud turbulence in idealized simulations. J. Atmos. Sci., 71, 2430-2451, https://doi.org/10.1175/JAS-D-13-0346.1.

, R. D. Sharman, and S. B. Trier, 2019: The role of gravity wave breaking in a case of upper-level near-cloud turbulence. Mon. Wea. Rev., 147, 4567-4588, https://doi.org/10.1175/ MWR-D-18-0445.1. 